\title{
Speed and Sensitivity of Phototransduction in Drosophila Depend on Degree of Saturation of Membrane Phospholipids
}

\author{
Alex S. Randall, ${ }^{1}$ Che-Hsiung Liu, ${ }^{1}$ Brian Chu, ${ }^{1}$ Qifeng Zhang, ${ }^{2}{ }^{\circledR S}$ Sidharta A. Dongre, ${ }^{3}{ }^{\circledR}$ Mikko Juusola, ${ }^{3,4}$ \\ ○Kristian Franze, ${ }^{1}$ Michael J.0. Wakelam, ${ }^{2}$ and ${ }^{\circ}$ Roger C. Hardie ${ }^{1}$ \\ ${ }^{1}$ Department of Physiology Development and Neuroscience, Cambridge University, Cambridge CB2 3EG, United Kingdom, ${ }^{2}$ Babraham Institute, Babraham, \\ Cambridge CB22 3AT, United Kingdom, ${ }^{3}$ Department of Biomedical Science, University of Sheffield, Sheffield S10 2TN, United Kingdom, and ${ }^{4}$ National Key \\ Laboratory of Cognitive Neuroscience and Learning, Beijing Normal University, Beijing 100875, China
}

\begin{abstract}
Drosophila phototransduction is mediated via a G-protein-coupled PLC cascade. Recent evidence, including the demonstration that light evokes rapid contractions of the photoreceptors, suggested that the light-sensitive channels (TRP and TRPL) may be mechanically gated, together with protons released by PLC-mediated $\mathrm{PIP}_{2}$ hydrolysis. If mechanical gating is involved we predicted that the response to light should be influenced by altering the physical properties of the membrane. To achieve this, we used diet to manipulate the degree of saturation of membrane phospholipids. In flies reared on a yeast diet, lacking polyunsaturated fatty acids (PUFAs), mass spectrometry showed that the proportion of polyunsaturated phospholipids was sevenfold reduced (from 38 to $~ 5 \%$ ) but rescued by adding a single species of PUFA (linolenic or linoleic acid) to the diet. Photoreceptors from yeast-reared flies showed a 2- to 3-fold increase in latency and time to peak of the light response, without affecting quantum bump waveform. In the absence of $\mathrm{Ca}^{2+}$ influx or in $\operatorname{trp}$ mutants expressing only TRPL channels, sensitivity to light was reduced up to $\sim 10$-fold by the yeast diet, and essentially abolished in hypomorphic G-protein mutants (Go $q$ ). PLC activity appeared little affected by the yeast diet; however, light-induced contractions measured by atomic force microscopy or the activation of ectopic mechanosensitive gramicidin channels were also slowed $\sim 2$-fold. The results are consistent with mechanosensitive gating and provide a striking example of how dietary fatty acids can profoundly influence sensory performance in a classical G-protein-coupled signaling cascade.
\end{abstract}

Key words: lipidomics; mechanosensitivity; phosphoinositide; phospholipase C; photoreceptors; PIP2

\section{Introduction}

Phototransduction in Drosophila is mediated by a G-proteincoupled PLC cascade, localized in a stack of $\sim 30,000$ microvilli together forming a light-guiding rhabdomere. The electrical response is characterized by exquisite sensitivity to single photons with kinetics $\sim 10-100 \times$ faster than in vertebrate rods (Yau and Hardie, 2009; for review, see Katz and Minke, 2009; Fain et al., 2010; Hardie, 2012). The response is mediated by $\mathrm{Ca}^{2+}$ permeable cation channels encoded by the transient receptor potential (trp) and trp-like (trpl) genes (Hardie and Minke, 1992;

Received March 13, 2014; revised Dec. 22, 2014; accepted Jan. 1, 2015.

Author contributions: A.S.R., M.J., M.J.O.W., and R.C.H. designed research; A.S.R., C.-H.L., B.C., Q.Z., S.A.D., M.J. K.F., and R.C.H. performed research; A.S.R., B.C., Q.Z., S.A.D., M.J., K.F., and R.C.H. analyzed data; A.S.R. and R.C.H. wrote the paper.

This research was supported by the Biotechnology and Biological Sciences Research Council (BBSRC; to M.J.O.W. and Q.Z., BBSRC Grant BB/G006865/1 to R.C.H., BB/H013849/1 to M.J., and BBSRC doctoral awards to A.S.R. and S.A.D.), the State Key Laboratory of Cognitive Neuroscience and Learning Open Research Fund (to M.J.), Jane and Aatos Erkko Foundation Fellowship (to M.J.), the Leverhulme Trust Grant (RPG-2012-567 to M.J.), and the UK Medical Research Council (Career Development Award to K.F.).

The authors declare no competing financial interests.

This article is freely available online through the J Neurosci Author Open Choice option.

Correspondence should be addressed to Roger C. Hardie, Department of Physiology Development and Neuroscience, Cambridge University, Cambridge CB2 3EG, UK. E-mail: rch14@cam.ac.uk.

DOI:10.1523/JNEUROSCI.1150-14.2015

Copyright $\odot 2015$ Randall et al.

This is an Open Access article distributed under the terms of the Creative Commons Attribution License (http://creativecommons.org/licenses/by/3.0), which permits unrestricted use, distribution and reproduction in any medium provided that the original work is properly attributed.
Phillips et al., 1992; Niemeyer et al., 1996; Reuss et al., 1997). Although Drosophila TRP was the prototypical member of the TRP ion channel family (Montell and Rubin, 1989; Hardie and Minke, 1992; Hardie, 2011), how TRP and TRPL, or their vertebrate TRPC homologs, are activated downstream of PLC remains controversial (for review, see Katz and Minke, 2009; Hardie, 2012; Montell, 2012). PLC hydrolyzes the membrane phospholipid, phosphatidylinositol 4,5 bisphosphate $\left(\mathrm{PIP}_{2}\right)$, generating DAG and inositol 1,4,5 trisphosphate $\left(\mathrm{Ins}_{3}\right)$. In general, neither DAG nor InsP $\mathrm{P}_{3}$ are effective activators of the light-sensitive channels when applied exogenously (for review, see Raghu and Hardie, 2009; Hardie, 2012); although slow activation of TRP channels by DAG was recently reported in excised patches (Delgado and Bacigalupo, 2009; Delgado et al., 2014). In contrast, both TRP and TRPL can be rapidly activated by polyunsaturated fatty acids (PUFAs; Chyb et al., 1999; Lev et al., 2012); however, a lipase that could release PUFAs from DAG in response to light has not been identified (Leung et al., 2008).

Two additional consequences of PLC activity have recently been implicated in channel activation. First, PLC reduces $\mathrm{PIP}_{2}$ levels, and second, it releases protons. Strikingly, the strict combination of $\mathrm{PIP}_{2}$ depletion and acidification rapidly and reversibly activates native TRP and TRPL channels (Huang et al., 2010). This might suggest that $\mathrm{PIP}_{2}$ binds to the channels, and when $\mathrm{PIP}_{2}$ dissociates, it exposes a protonatable site, which mediates activation by protons. However, evidence suggests that $\mathrm{PIP}_{2}$ de- 
pletion might also act in a mechanical sense; namely, by removing its bulky inositol headgroup, hydrolysis of $\mathrm{PIP}_{2}$ directly affects the physical properties of the lipid bilayer. Recently a direct manifestation of this was observed as rapid light-evoked contractions of photoreceptors (Hardie and Franze, 2012). Involvement of membrane physical properties in channel activation was also described previously (Parnas et al., 2009).

If mechanical gating is involved, we predicted that the response to light should be influenced by altering the physical properties of the membrane. To this end we used diet to manipulate the degree of saturation of membrane phospholipids-a key factor controlling membrane stiffness and elasticity (Brenner, 1984; Rawicz et al., 2000). Strikingly, increasing the proportion of saturated phospholipids resulted in a 2 - to 3 -fold increase in response latency, which appeared to be mediated downstream of PLC and was associated with a slowing of the light-induced contractions. The results are consistent with mechanical gating and provide a striking demonstration of how dietary fatty acids can influence a defined step in a classical G-protein-coupled signaling cascade.

\section{Materials and Methods}

Flies (Drosophila melanogaster) were reared on various diets (see below) in the dark at $25^{\circ} \mathrm{C}$. The wild-type strain was Oregon; for some experiments white-eyed mutants ( $w^{1118}$ or $\left.c n, b w\right)$ were used, which are indistinguishable in terms of whole-cell electrophysiology. Mutants used included: $w^{1118} ; ; \operatorname{tr} p^{343}$, a null mutant of the major light-sensitive TRP channel (Scott et al., 1997); $c n, b w, \operatorname{trpl}^{302}$, a null mutant of the TRPL channel (Niemeyer et al., 1996); and $c n, b w, G \alpha q^{1}$, a severe hypomorph of the $\mathrm{G}_{\mathrm{q}}$-protein $\alpha$-subunit, expressing $\sim 1 \%$ functional protein (Scott et al., 1995). For $\mathrm{pH}$ microfluorometry we used $p[R h 3]$, nina $E^{8}$ flies (Wardill et al., 2012) expressing the UV rhodopsin Rh3 on a nina $E^{8}$ background (near null mutant for the normal Rh1 opsin).

Food. The yeast-based diet (YF diet) consisted of the following: $100 \mathrm{ml}$ of tap water, $1 \mathrm{~g}$ of agar, $8 \mathrm{~g}$ of baker's yeast, $5 \mathrm{~g}$ of sucrose, $5 \mathrm{ml}$ of nipagin $(2.9 \%)$, and $25 \mathrm{mg}$ of $\beta$-carotene. Flies were reared on either this YF diet or with the addition of $50 \mu \mathrm{l} / 100 \mathrm{ml}$ of a single species of fatty acid: linoleic acid (LA; 18:2), linolenic acid (LNA; 18:3), oleic acid (OL; 18:1), stearic acid (ST: 18:0), or palmitic acid (PAL: 16:0). For food preparation, tap water; agar, yeast, and sucrose were mixed at room temperature, before microwaving for $2 \mathrm{~min}$. Nipagin, $\beta$-carotene, and fatty acids (when used) were added after cooling, and mixed in using an electric blender. Control flies were also reared on standard plant/yeast-based medium ( $8.5 \mathrm{~g}$ of cornmeal, $0.9 \mathrm{~g}$ of agar, $1.5 \mathrm{~g}$ of yeast, $7.5 \mathrm{~g}$ of glucose, and $5 \mathrm{ml}$ nipagin $/ 100 \mathrm{ml}$ water).

Electrophysiology. Whole-cell patch-clamp recordings of photoreceptors from dissociated ommatidia from newly eclosed adult flies of either sex were made as previously described (Hardie et al., 2002) on an inverted Nikon Eclipse TE300 microscope. Standard bath contained the following (in mu): $120 \mathrm{NaCl}, 5 \mathrm{KCl}, 10 \mathrm{~N}$-Tris-(hydroxymethyl)methyl-2-amino-ethanesulphonic acid (TES), $4 \mathrm{MgCl}_{2}, 1.5 \mathrm{CaCl}_{2}, 25$ proline, and 5 alanine, $\mathrm{pH}$ 7.15. The intracellular pipette solution was as follows (in mM): $140 \mathrm{~K}$ gluconate, $10 \mathrm{TES}, 4 \mathrm{Mg}$-ATP, $2 \mathrm{MgCl}_{2}, 1 \mathrm{NAD}$, and 0.4 Na-GTP, pH 7.15. Chemicals were obtained from SigmaAldrich. Recordings were made at room temperature $\left(20 \pm 1^{\circ} \mathrm{C}\right)$ at -70 $\mathrm{mV}$ (including correction for $-10 \mathrm{mV}$ junction potential) using electrodes of resistance $\sim 10-15 \mathrm{M} \Omega$. Series compensation of $>80 \%$ was applied for macroscopic responses, but not for sampling quantum bumps and dark noise. Data were sampled at $0.5-2 \mathrm{kHz}$ and filtered (4-pole Bessel) at $0.2-1 \mathrm{kHz}$ using Axopatch 200 or 1D amplifiers and pClamp software (Molecular Devices). Quantum bumps and spontaneous dark events were analyzed from favorable recordings (baseline noise SD typically 0.3-0.5 pA) using Mini analysis (Jaejin Software), setting a peak threshold criterion of $0.5 \mathrm{pA}$ and area threshold of $8-12 \mathrm{pA} . \mathrm{ms}$ for dark events and $2 \mathrm{pA}$ and 40 pA.ms for quantum bumps, respectively. Unless otherwise stated, photoreceptors were stimulated via a green (540 $\mathrm{nm}$ ) ultrabright LED; intensities were calibrated in terms of effectively absorbed photons by counting quantum bumps at low intensities. Because responses scale strictly linearly with intensity over a substantial range of intensities (Henderson et al., 2000), sensitivity within this linear range can be measured from response amplitudes to flashes of fixed intensities.

For $\mathrm{pH}$ microfluorometry, the fluorescent $\mathrm{pH}$ indicator 8-hydroxypyrene-1,3,6-trisulphonic acid (HPTS; $500 \mu \mathrm{M}$ ) was loaded into photoreceptors via the patch electrode, allowing $\sim 2-3 \mathrm{~min}$ for equilibration before making measurements as previously described (Huang et al., 2010). Excitation light ( $470 \mathrm{~nm}$ ) was delivered from a high-power LED and fluorescence of the whole-cell measured via a photomultiplier tube (Cairn Research) using $515 \mathrm{~nm}$ dichroic and OG515 long-pass filters. Absolute $\mathrm{pH}$ shifts $(\Delta p H)$ can be estimated using single wavelength fluorometry if the starting $\mathrm{pH}$ value $\left(\mathrm{pH}^{\text {start }}\right)$ is known (Schwiening and Willoughby, 2002):

$$
\Delta p H=\log \left(F / F_{0}\right)-\log \left(1-F / F_{0}-1\right) \times 10^{(\text {pHstart-pKa) }}
$$

where $F$ is the instantaneous fluorescence and $F_{o}$ is the fluorescence at the start of the recording. pKa for HPTS was taken as 7.18 (Schwiening and Willoughby, 2002) and $\mathrm{pH}^{\text {start }} 7.15(\mathrm{pH}$ of the bath and patch pipette solutions).

In vivo electrophysiology. Flies (1-10 d post-eclosion females) were kept in darkness at $19^{\circ} \mathrm{C}$ for at least $3 \mathrm{~d}$ before the experiments. For intracellular recordings, flies were immobilized in a brass fly holder with beeswax, as described previously (Juusola and Hardie, 2001). Conventional sharp microelectrodes (120-220 M $\Omega$ ) were pulled from borosilicate glass with a Sutter Instruments P2000 puller, filled with $3 \mathrm{M} \mathrm{KCl}$ solution and inserted via a small hole cut in the dorsal cornea sealed with Vaseline. A blunt reference electrode, filled with fly ringer, was inserted into the head near the ocelli. The fly's head was maintained at $20 \pm 1^{\circ} \mathrm{C}$ by a feedback-controlled Peltier device. Recordings were performed using the discontinuous (switched) clamp method with a switching frequency of up to $40 \mathrm{kHz}$. The selected R1-R6 photoreceptors typically had resting potentials $<-55 \mathrm{mV}$ in darkness and $\sim 40-60 \mathrm{mV}$ responses to a saturating $10 \mathrm{~ms}$ light pulse (estimated to contain $\sim 10^{5}$ photons).

Photoreceptors were stimulated with a high-power LED (Seoul Z-Power LED P4 star, white, 100 lumens), driven by an Opto-LED (Cairn Research). The LED was connected to a randomized quartz fiber optic bundle, fitted with a lens and a pinhole $\left(\sim 2^{\circ}\right.$ as seen by the flies), centered on the photoreceptor's receptive field using a Cardan arm device. Both the stimuli and the voltage responses were low-pass filtered (6-pole Bessel) at $500 \mathrm{~Hz}$, and sampled at $1 \mathrm{kHz}$ using a 12-bit A/D converter (National Instruments), controlled by a custom-written software system, Biosyst (Juusola and Hardie, 2001; Juusola and de Polavieja, 2003) in MATLAB (MathWorks).

The analytical and information theoretical methods used have been described in detail previously (Juusola et al., 1994; Juusola and Hardie, 2001; Juusola and de Polavieja, 2003), and are briefly summarized here. We selected a highly variable $1 \mathrm{~s}$ long naturalistic light-intensity time series sequence (NS; 10,000 points) from the van Hateren stimulus collection (van Hateren, 1997), with a power spectrum following $\sim 1 / f$ statistics (where $f=$ temporal frequency). The NS, with mean effective intensity of $\sim 10^{5}$ photons/s, was played back at $10 \mathrm{kHz}$ and repeated 50-100 times, while continuously recording the photoreceptor's voltage response. The first 5-20 traces showed short-term adaptive trends and were rejected from the analysis.

In each recording, the mean was the signal, and the noise was the difference between individual traces and the signal. Therefore, from $n$ trials we obtained one signal trace and $n$ noise traces. The signal and noise traces were divided into $50 \%$ overlapping stretches and windowed with a Blackman-Harris 4-term window, each giving three 500 point long samples. Twenty consecutive traces were selected from the most stable continuous segment in the recorded voltage responses, from which we obtained 60 spectral samples for the noise, and 3 spectral samples for the signal. These were averaged, respectively, to improve the estimates.

Signal-to-noise ratio, $S N R(f)$, estimates of the voltage responses were calculated from their signal and noise power spectra, $\left\langle|S(f)|^{2}\right\rangle$ and $<|N(f)|^{2}>$, respectively, as their ratio, where || denotes the norm and 
A

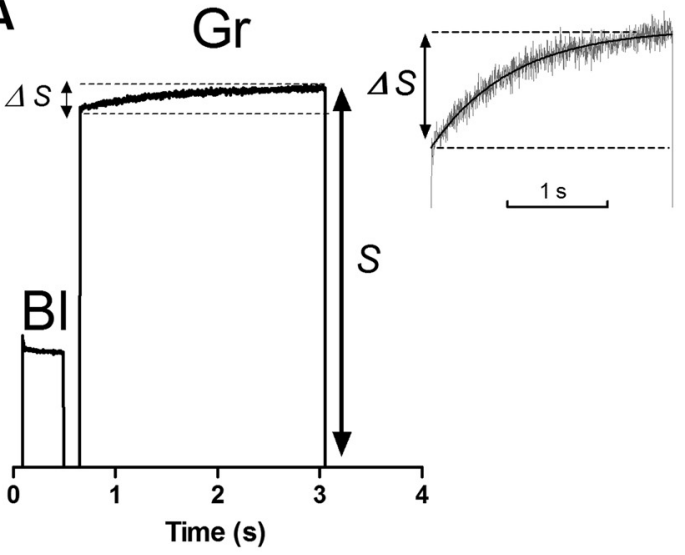

C

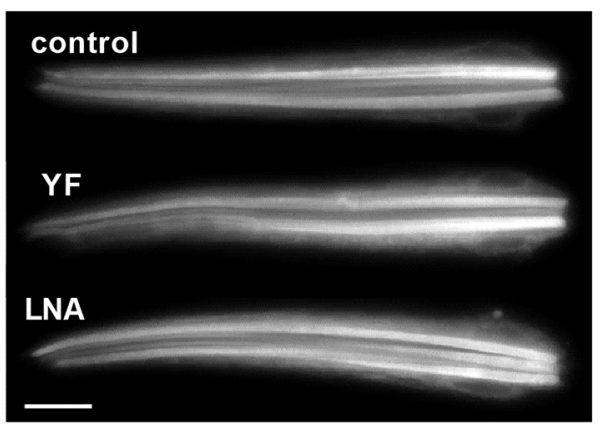

B

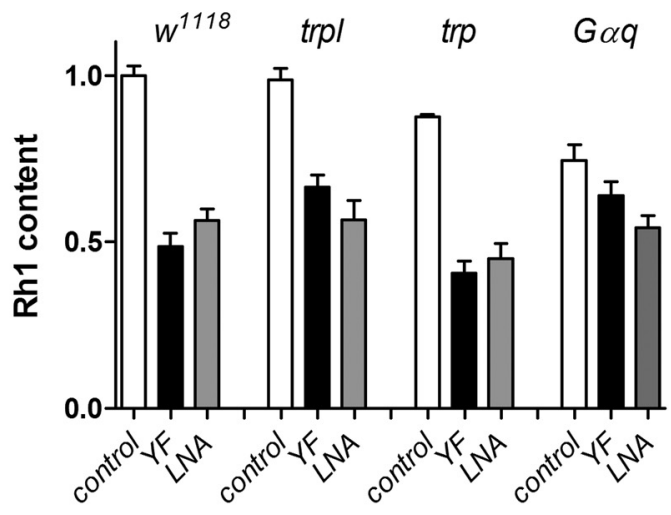

D

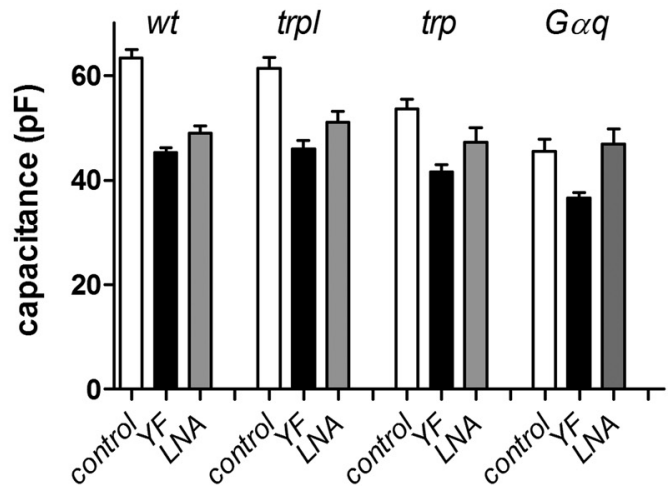

Figure 1. Diet has only minor effects on visual pigment and morphology. A, Reflectance/scattered light measurements from deep pseudopupil of intact white-eyed fly $\left(w^{1118}\right)$ : rhodopsin was first converted to metarhodopsin $(\mathrm{M})$ by bright blue $(\mathrm{BI}=470 \pm 20 \mathrm{~nm}$ ) excitation, and then reconverted to the rhodopsin state $(\mathrm{R})$ by long wavelength green illumination ( $\mathrm{Gr}=550 \pm 50 \mathrm{~nm}$ ). Because $M$ absorbs maximally $570 \mathrm{~nm}$ and $R$ at $480 \mathrm{~nm}$, less long wavelength light is absorbed by the eye as $M$ is photoreisomerized back to $R$ and the intensity of the reflected/back-scattered green light (S) increases with an exponential time constant reflecting the rate of $M>R$ conversion (inset on expanded scale). The relative increase during this phase $(\Delta S / S)$ provides a measure of the concentration of visual pigment in the eye. $\boldsymbol{B}$, Relative rhodopsin (Rh1) content in wild-type (wt), trpl, trp, and $G \alpha q$ mutants derived from $\Delta S / S$ values normalized to wild-type $\left(w^{1118}\right)$ control flies reared on normal diet. In most cases values for flies reared on both YF and LNA diets were reduced $\sim 2$-fold compared with control diet (white bars), but YF and LNA-reared flies in each genotype showed no significant differences from each other (one-way ANOVA). Mean $\pm \mathrm{SEM} ; n=6-10$ flies each. C, Dissociated ommatidia from flies reared on normal, YF, and LNA diets appeared similar (fluorescent micrographs of ommatidia from wild-type flies expressing GFP-tagged arrestin to highlight rhabdomeres). Scale bar, $10 \mu \mathrm{m}$. $D$, Whole-cell capacitances in wild-type, trpl, trp, and $G \alpha q$ flies reared on control, YF, and LNA diets (mean \pm SEM; $n=8-27$ cells each). In each genotype, values on YF and LNA diets were statistically indistinguishable (one-way ANOVA), although usually slightly lower than on control diet.

$<>$ the average over the different stretches. Note that since $S N R(f)$ estimates of YF, LNA control photoreceptor outputs were calculated using the same number of traces, and their comparison was immune to data-size bias.

To estimate information transfer rates of photoreceptor voltage responses, we used both the classic Shannon formula and the triple extrapolation method (Juusola and de Polavieja, 2003). But since both methods provided similar estimates (cf. Song and Juusola, 2014), showing consistent differences between the test (YF and LNA) and control groups, we show only the information rates, $C$, obtained from the Shannon formula (Fig. 5):

$$
C=\int_{\min }^{\max } \log _{2}(S N R(f)+1) d f
$$

where $\min =2 \mathrm{~Hz}$ and $\max =500 \mathrm{~Hz}$ (resulting from $1 \mathrm{kHz}$ sampling rate and 500 point window size).

Electroretinograms were recorded as described previously (Satoh et al., 2010) from flies of either sex immobilized with low melting point wax in truncated pipette tips using low resistance $(\sim 10 \mathrm{M} \Omega)$ glass microelectrodes filled with fly Ringer $\left(140 \mathrm{~mm} \mathrm{NaCl}, 5 \mathrm{KCl}, 1.5 \mathrm{CaCl}_{2}\right.$, and 4 $\mathrm{MgCl}_{2}$ ), one inserted into the eye and one into the head capsule near the ocelli. Light from a $100 \mathrm{~W}$ halogen lamp was filtered by a Schott OG550 long-pass filter and glass neutral density filters and delivered to the eye by a fluid-filled light guide positioned within $5 \mathrm{~mm}$ of the fly's head. Signals were amplified by a NeuroLog NL102 DC (Digitimer) preamplifier and sampled and analyzed using pClamp software (Molecular Devices).

Measurements of Rhodopsin concentration. Fly metarhodopsin (M) is thermostable and absorbs maximally at $\sim 570 \mathrm{~nm}$, while the rhodopsin (R) state absorbs maximally at $480 \mathrm{~nm}$. The $\mathrm{M}$ and $\mathrm{R}$ states are photointerconvertible and exist in a photo-equilibrium, determined by the spectral content of illumination and the $\mathrm{R}$ and $\mathrm{M}$ photosensitivity spectra (Minke and Kirschfeld, 1979; Belusic et al., 2010). Long wavelength light reflected and scattered back out of the eye is more effectively absorbed by $\mathrm{M}$ than it is by $\mathrm{R}$. Consequently, when delivered after first establishing a photo-equilibrium with blue light (generating $\sim 70 \% \mathrm{M}$ ), the intensity of back-scattered long wavelength light increases as $\mathrm{M}$ is photoreisomerized back to $\mathrm{R}$ with a single exponential time course that provides a direct measure of the rate of photon absorptions by $\mathrm{M}$. The increase in reflected/back-scattered light as $\mathrm{M}$ is reconverted to $\mathrm{R}$ provides a measure of the concentration of visual pigment and was used to compare visual pigment concentrations in flies reared on different diets (Fig. 1A).

Optomotor behavior experiments. For flight simulator experiments, we used 3- to 7-d-old female flies, reared in a $12 \mathrm{~h}$ dark/light cycle. Flies were tethered in a classic torque meter (Tang and Guo, 2001), with heads fixed, and lowered by a manipulator in the center of a black-white cyl- 
inder (spectral full-width: $380-900 \mathrm{~nm}$ ). A flying fly saw a continuous $\left(360^{\circ}\right)$ stripe scene. After viewing the still scene for $1 \mathrm{~s}$, it was spun counterclockwise by a linear stepping motor for $2 \mathrm{~s}$, stopped for $2 \mathrm{~s}$ before rotating clockwise for $2 \mathrm{~s}$, and stopped again for $1 \mathrm{~s}$. This $8 \mathrm{~s}$ stimulus was repeated 10 times and each trial, together with the fly's yaw torque responses, was sampled at $1 \mathrm{kHz}$ (Wardill et al., 2012). Flies followed the scene rotations, generating yaw torque responses (optomotor responses to right and left), the strength of which reflects the strength of their motion perception. Stimulus parameters for the moving stripe scenes were as follows: azimuth $\pm 360^{\circ}$, elevation $\pm 45^{\circ}$, wavelength $14^{\circ}$, and contrast 1.0 , as seen by the fly. For slow scene rotation, the velocity was $45^{\circ} \mathrm{s}$ and for fast rotation, $180^{\circ} / \mathrm{s}$.

Atomic force microscopy. Atomic force microscopy (AFM) measurements were made as previously described (Hardie and Franze, 2012) from dissected retinae attached to glass slides using Cell-Tak Cell and Tissue Adhesive (BD Biosciences) in normal bath solution. Monodisperse polystyrene beads $(37.28 \pm 0.34$ $\mu \mathrm{m}$; microParticles) were glued to silicon cantilevers (Arrow TL1; NanoWorld; nominal spring constant: $0.03 \mathrm{~N} / \mathrm{m}$ ). The cantilevers were mounted on a JPK NanoWizard 3 AFM (JPK Instruments), placed on the same inverted microscope (Nikon Eclipse TE300) used for whole-cell patch-clamp measurements. The cantilever probe was approached onto the retina where it stayed in contact with the distal ends of a small group of photoreceptors, with a set force of $200 \mathrm{pN}$. Cantilever deflection was maintained constant and $z$-piezo position sampled at $2 \mathrm{kHz}$ and synchronized to the triggered light pulses using pClamp software (Molecular Devices).

Lipidomics. For each sample 100-200 recently eclosed $(<2$-d-old) flies were transferred to a prechilled $50 \mathrm{ml}$ Falcon tube and dark adapted by wrapping the tubes in aluminum foil. The tubes were then immersed in liquid nitrogen for $1 \mathrm{~min}$, before vortexing for $\sim 1$ min to separate the heads. Heads were collected and freeze dried by storing in $10 \mathrm{ml}$ acetone at $-20^{\circ} \mathrm{C}$ for $3-4 \mathrm{~d}$. Between 100 and 200 heads per sample were manually collected under a stereo microscope after draining the acetone and drying on Whatman filter paper and stored again at $-20^{\circ} \mathrm{C}$ before lipid extraction. In some cases, retinae were dissected from the freeze-dried heads using a blunt, flattened insect pin (Matsumoto et al., 1982). Lipid extraction and lipidomic analysis of all major lipids and bis- and tris-phosphorylated phosphoinositides was performed as previously described (Clark et al., 2011; Norton et al., 2011) using an AB Sciex 4000QTRAP mass spectrometer connected to a Shimadzu Prominence HPLC system (Shimadzu Scientific Instruments).

\section{Results}

To manipulate membrane phospholipid composition, flies were reared on diets based on yeast, sucrose, and agar. Yeast
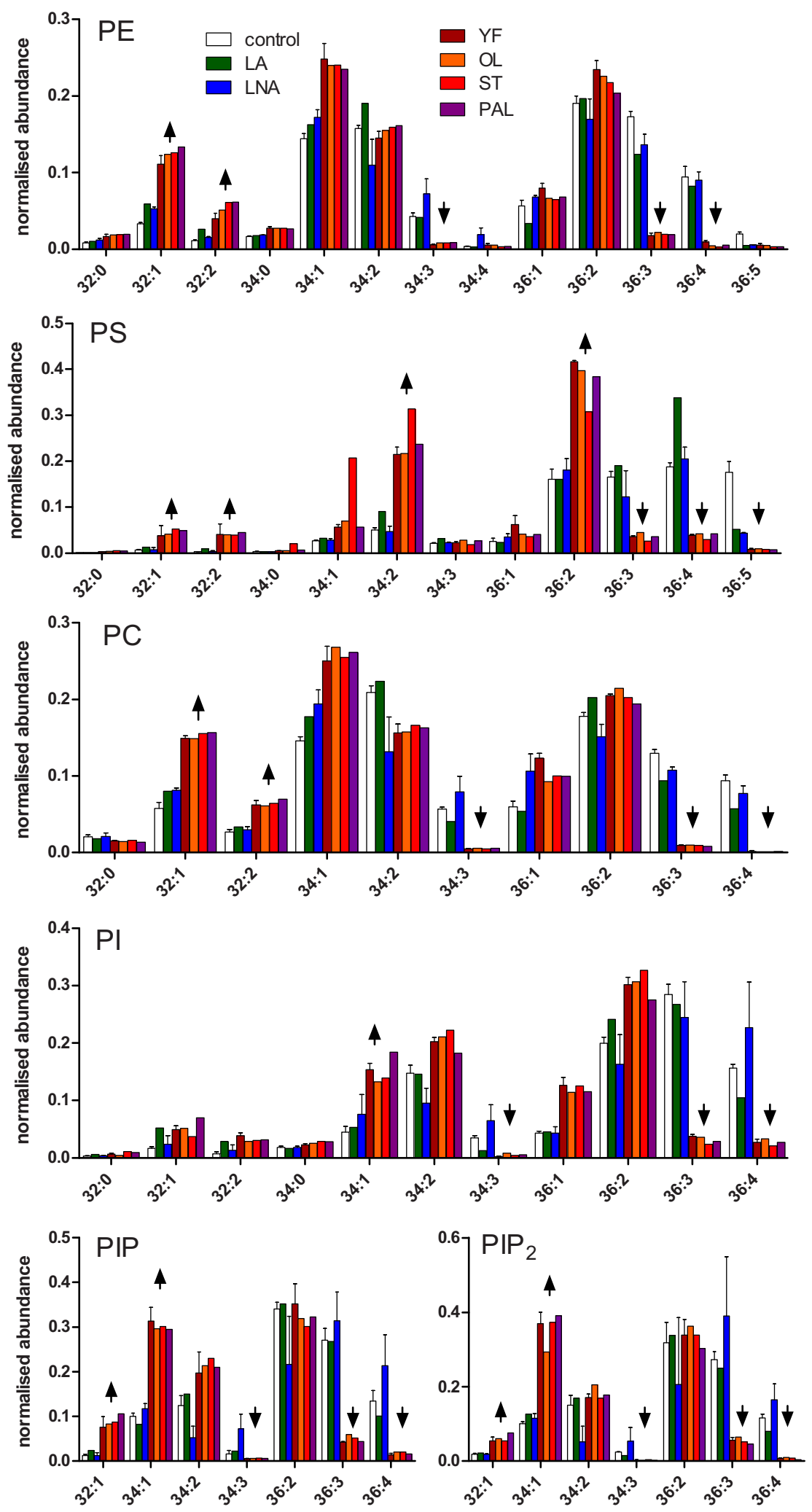

Figure 2. Lipidomic profile of major phospholipid classes in fly heads. Normalized relative abundance of different fatty acid species are shown for fly heads reared on normal diet (control) and yeast diet (YF) as well as YF supplemented with saturated/ monounsaturated FAs (0L 18:1, ST 18:0, PAL 16:0) or PUFAs (LA 18:2, LNA 18:3). Arrows highlight species that were at least twofold reduced or increased on the YF diet. All these changes were rescued by supplement of PUFAs (LA or LNA), but not by saturated/monounsaturated FAs (OL, ST, or PAL). Mean \pm SEM; $n=4$ (control, YF, and LNA), or $n=2$ (OL, LA, PAL, and ST) replicates (error bars not shown). Note also the consistency of results, particularly across the saturated/monounsaturated FA series (YF, OL, ST, or PAL: "warm" colors). Numbers (e.g., 36:2) refer to number of carbon atoms: number unsaturated bonds in both acyl chains considered together. 

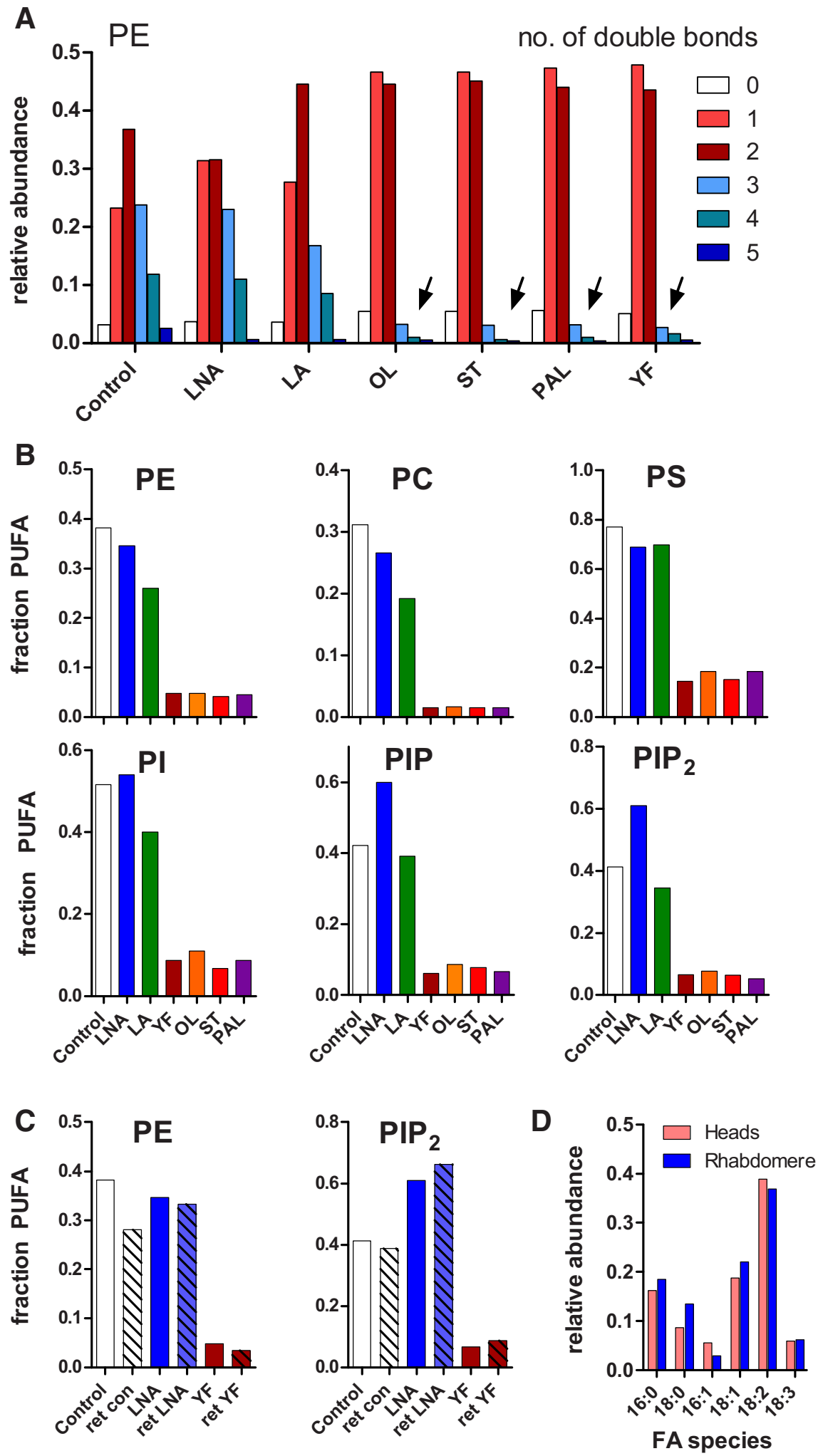

Figure 3. Proportion of polyunsaturated phospholipids in flies reared on different diets. Analysis of lipidomic data from Figure 2 shows degree of saturation of phospholipids. $\boldsymbol{A}$, Distribution of PE species with different numbers of double bonds (numbers refer to double bond number in both acyl tails together). Flies reared on control diet have substantial proportions of polyunsaturated species ( 3 or more double bonds, blue colors). These were greatly reduced (arrows) on YF diet and diets supplemented with saturated or monounsaturated FAs (OL, ST, or PAL), but rescued by supplements of PUFAs (LNA or LA). $\boldsymbol{B}$, Data further simplified to show fraction of each phospholipid class with unambiguous PUFA acyl tails ( 3 or more double bonds): there was a 5- to 20-fold reduction (mean 7-fold) on YF or OL/ST/PAL diets across all phospholipid classes. $C_{\text {, Comparison of PE and PIP }}$ data (fraction of phospholipids containing PUFAs) from whole heads (data replotted from $\boldsymbol{B}$ ) and lipids extracted from dissected retinae (hatched bars: "ret") for the three main diets (control, YF, and LNA). A similar close correspondence between whole-head and retina profiles lipids contain saturated and monounsaturated fatty acids, but little or no PUFAs (Ejsing et al., 2009; Carvalho et al., 2012). PUFA content of the diet can thus be simply controlled by addition of specific PUFAs to the basic yeast diet. Yeast-based diets also lack vitamin $\mathrm{A}$ and flies reared on yeast have an $\sim 500$-fold reduction in rhodopsin (Isono et al., 1988). However, with addition of $\beta$-carotene (as precursor for the chromophore, 3 -OH retinal), rhodopsin levels were restored to $\sim 50 \%$ of normal, but not further influenced by addition of PUFA supplement to the diet (Fig. 1B). Flies reared on the basic yeast + $\beta$-carotene diet (referred to as YF, for yeast food) were overtly normal with no obvious defects in morphology of the retina or photoreceptors (Fig. 1C). Nevertheless, in whole-cell recordings, despite overlap in values, there was on average a slight $(\sim 20 \%)$ reduction in capacitance (a sensitive measure of microvillar membrane area) in flies reared on both YF and LNA diets (Fig. 1D). The reduction in rhodopsin levels can be expected to reduce sensitivity (quantum catch) proportionally, but neither this, nor the slight reduction in microvillar area, would be expected to influence voltage-clamped response kinetics, which show no correlation with capacitance or rhodopsin level (R. C. Hardie, unpublished results). Importantly, YFreared flies were indistinguishable in both respects from LNA-reared flies, which represent the most direct relevant control in most experiments.

\section{Lipidomic analysis}

The major classes of phospholipids, i.e., phosphatidylcholine (PC), phosphatidylethanolamine (PE), phosphatidylserine (PS), and phosphoinositides (PI and $\mathrm{PIP}_{\mathrm{n}}$ ), were extracted, separated, and analyzed by mass spectrometry. Lipid species were identified by total carbon number and number of unsaturated bonds in the acyl tails, e.g., 36:2, which might, for example, represent two similar 18:1 (oleic acid) acyl tails or 18:2 (linoleic acid) plus 18:0 (stearic acid). According to previous lipidomic analysis (Ejsing et al., 2009; Carvalho et al., 2012),

was also found for PC, PS, PI, and PIP (data not shown). D Comparison of FA species in phospholipids in present study (heads from flies reared on normal diet) with a recent lipidomic study of purified rhabdomeric membranes (Muñoz et al., 2013). For this comparison, our data (for both acyl species combined) have been assigned the most likely single acyl tails on the basis of published data from Drosophila (Carvalho et al., 2012) and summed across all phospholipid classes. 
species such as $36: 2$ and 34:2 in yeast correspond to phospholipids with two monounsaturated acyl tails (e.g., 18:1 and/or 16:1), and PUFAs are present in only trace amounts across all lipid species in yeast. Our analysis confirmed this for the phospholipid species initially present in the yeast food, with an overall reduction of $\sim 20$-fold in the concentration of polyunsaturated phospholipids (with three or more double bonds in both tails considered together) compared with the plant-based control diet $(1.8 \mu \mathrm{g} / \mathrm{g}$ in YF, cf. $37 \mu \mathrm{g} / \mathrm{g}$ in control food).

Lipidomic analysis of fly heads reared on the respective diets showed that the lack of PUFAs in the YF diet was reflected in corresponding marked differences in the fatty acid composition of all the major phospholipids in the head (Figs. 2, 3). In particular, while monounsaturated species were little affected, or increased in flies reared on the YF diet, unambiguous polyunsaturated species (with three or more double bonds: 36:3, 36:4) were greatly reduced in all classes of phospholipids (Figs. 2, 3). When reared on the normal diet, $38 \%$ of the total phospholipid pool contained at least one polyunsaturated acyl tail; however, on the YF diet this was reduced sevenfold to $\sim 5 \%$. Supplementation of the diet with a single PUFA species (LNA, 18:3 or LA, 18:2) effectively restored the proportion of polyunsaturated phospholipids, while saturated (PAL or ST) or a monounsaturated fatty acid (FA; OL, 18:1) failed to do so (Fig. $3 B$ ). Flies reared on the YF diet also tended to have slightly shorter acyl tails as previously reported (Carvalho et al., 2012). However, differences were very slight; for example, the average (combined) acyl tail length for PE (the major phospholipid in Drosophila) was $35.4 \mathrm{C}$ atoms on control diet and 34.8 on YF diet.

$\mathrm{PIP}_{2}$, which is the substrate for the key effector enzyme PLC, conformed to the general pattern of the other phospholipids: the predominant $\mathrm{PIP}_{2}$ species in heads of flies reared on normal food were (in order of abundance) $36: 2>36: 3>34: 2 \approx$ $36: 4>34: 1$. In flies reared on the YF diet the polyunsaturated species (36:4 and 36:3) were almost eliminated, primarily at the expense of an increase in 34:1 (Fig. 2). Both LNA and LA supplements restored or even increased levels of $36: 3$ and 36:4, while PAL, ST, and OL again failed to do so (Figs. 2, 3).

These profiles were derived from lipids extracted from whole heads, raising the question of whether they are representative of phospholipids in the photoreceptors. To address

E
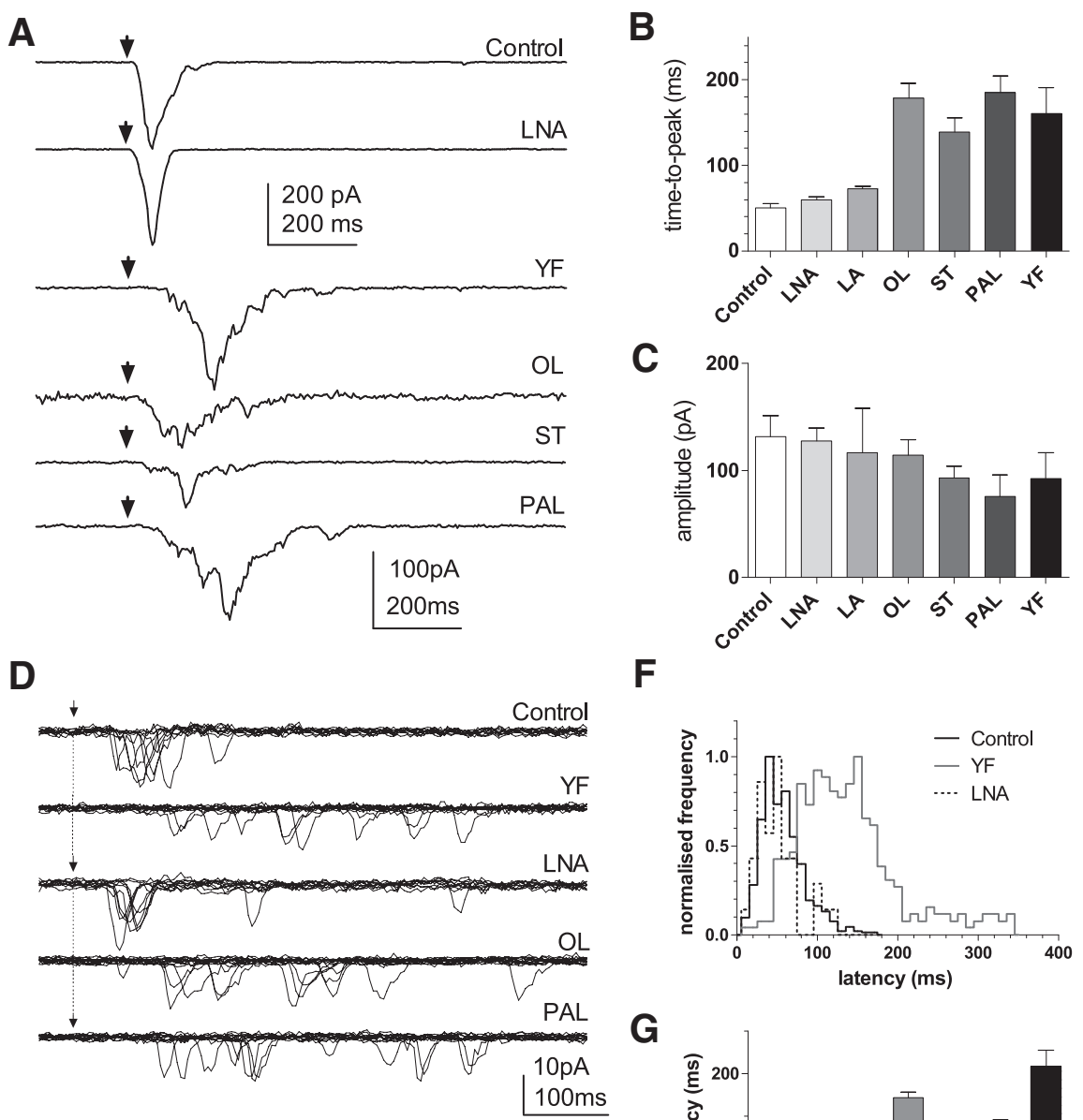

$\mathbf{F}$
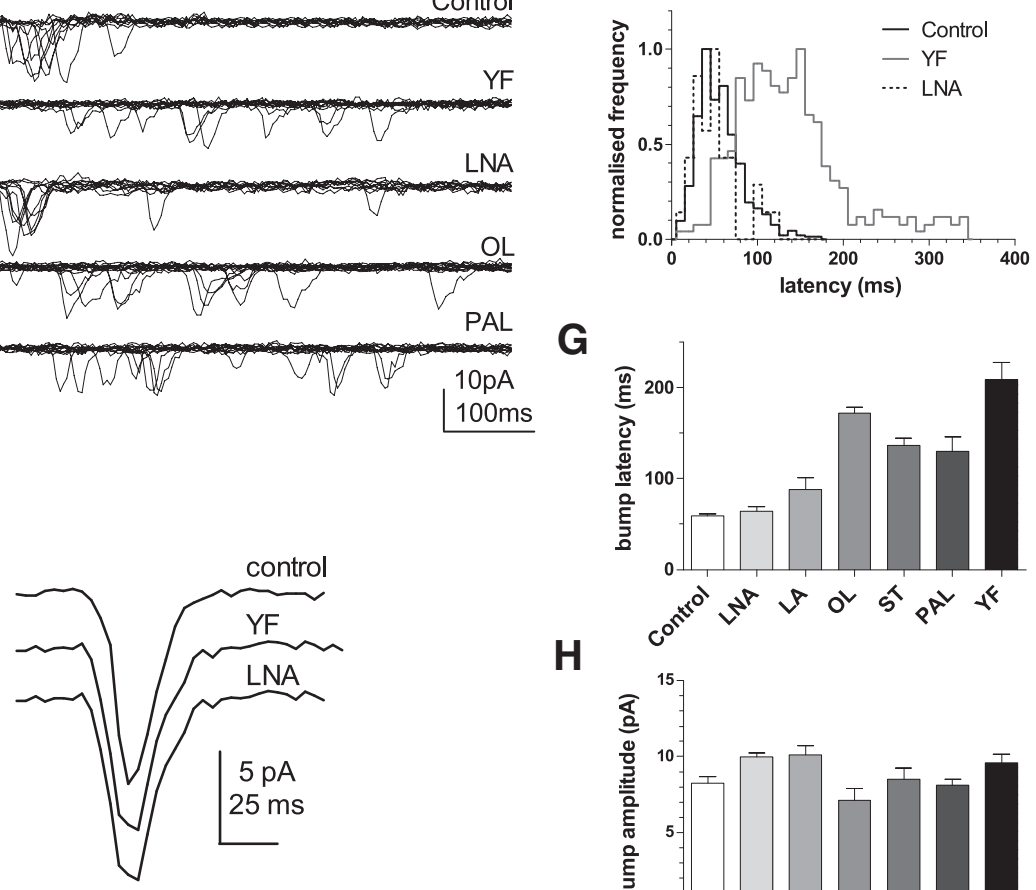

G

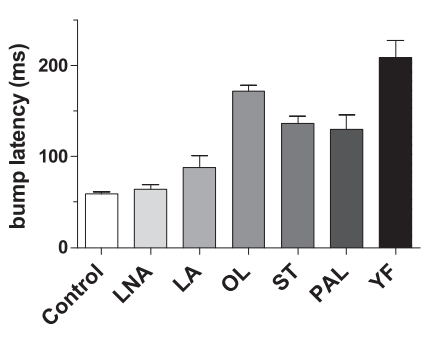

H

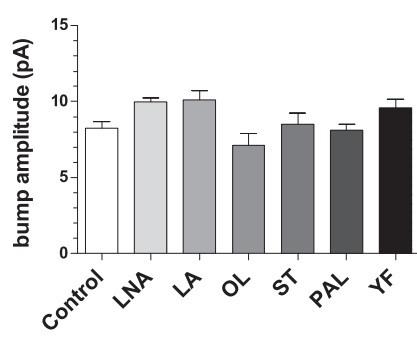

Figure 4. Light responses are slower in flies reared on PUFA-deficient diets. $A$, Representative responses to $1 \mathrm{~ms}$ flashes (arrows) containing $\sim 80$ effective photons in wild-type photoreceptors reared on normal diet (control), YF diet, and the same diet supplemented with $50 \mu \mathrm{l} / 100 \mathrm{ml} \mathrm{LNA}, 0 \mathrm{~L}, \mathrm{ST}$, and PAL. $\boldsymbol{B}$, Time to peak of flash responses (as in $A$ ) in flies reared on control (mean \pm SEM; $n=12$ cells and YF diets and YF diets with different fatty acid supplements). Time to peak in flies reared on all PUFA-deficient diets (YF, $n=9 ; \mathrm{ST}, n=$ $5 ; \mathrm{PAL}, n=3 ; 0 \mathrm{~L}, n=3$ cells) were $2-3 \times$ longer than in control ( $p<0.05$, one-way ANOVA, Bonferroni correction). PUFAs (LNA, $n=8$ and $n=13$ cells) rescued the rapid response. $C$, Amplitude of responses tended to be reduced on PUFA-deficient diets but did not reach significance. $\boldsymbol{D}$, Representative superimposed quantum bumps induced by brief ( $1 \mathrm{~ms}$ ) flashes containing on average less than one effectively absorbed photon. Bumps had relatively short latencies in flies reared on normal diet but long and variable latencies on YF diets. LNA, but not OL or PAL, rescued the short latency. $\boldsymbol{E}$, Averaged bump waveforms on control YF and LNA diets were indistinguishable. $\boldsymbol{F}$, Representative examples of normalized bump latency distributions from photoreceptors of flies reared on control, $Y F$, and LNA diets. G, Mean bump latency ( \pm SEM across cells) on different diets were slower on $\mathrm{YF}, 0 \mathrm{~L}$, $S \mathrm{~T}$, and PAL diets $(p<0.05$, one-way ANOVA, Bonferroni correction). $\boldsymbol{H}$, Mean bump amplitudes on different diets were similar.

this we dissected $\sim 100$ retinae from freeze-dried tissue of flies reared on each of the three main diets (normal, YF, and YF + LNA), and found closely overlapping profiles, with again a massive reduction in PUFAs (mean: 9.8-fold reduction aver- 
A
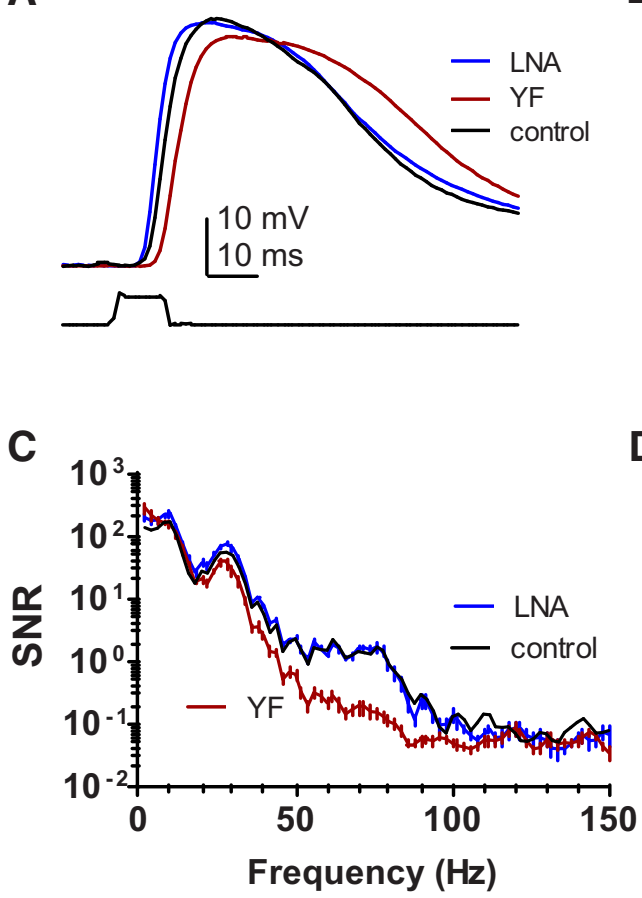

Effect of diet on the light response In whole-cell recordings made from dissociated ommatidia of flies reared on the YF diet, it was immediately apparent that responses to brief test flashes were greatly slowed (Fig. 4). As previously reported, time to peak in flies reared on normal food is typically $\sim 40-60 \mathrm{~ms}$, but in flies reared on YF diet responses were two to three times slower $(\sim 120 \mathrm{~ms})$. Time to peak was restored to normal by addition of a single PUFA species $(50 \mu \mathrm{l} / 100 \mathrm{ml})$ to the diet, with both LNA (18:3) and LA (18:2) rescuing the normal rapid response. In contrast, addition of the same amount of saturated (PAL and ST) or monounsaturated fatty acid (OL) to the diet resulted in no improvement (Fig. $4 A, B)$.

The macroscopic response to a brief flash is that the linear summation of the underlying responses to single photons (quantum bumps) and kinetics is consequently jointly determined by the convolution of bump waveform and bump latency (Henderson et al., 2000). To see which was responsible for the slower responses, we recorded responses to single photons (quantum bumps) by delivering brief ( $\leq 1 \mathrm{~ms}$ ) dim flashes containing on average less than a single effective photon. Quantum bump amplitude ( $\sim 9 \mathrm{pA})$, waveform, and duration $\left(t_{(1 / 2)} \sim 20 \mathrm{~ms}\right)$ were indistinguishable across all diets (Fig. $4 E, H$ ); however, bump latency was specifically prolonged and the latency distribution broadened on YF diet, once again fully rescued by addition of LNA or LA, but not saturated or monounsaturated fatty acids to the diet (Fig. $4 D, F, G$ ). In contrast, overall sensitivity (response amplitude) was little affected by diet. Because of the clear rescue of response kinetics by polyunsaturated, but not saturated or monounsaturated FA supplements, all subsequent experiments were performed on just three basic diets: normal (control) food, YF, and YF + LNA (LNA diet).

We next explored the consequence of dietary manipulation for visual performance in intact animals. First, recordings of voltage response of photoreceptors using intracellular sharp microelectrodes in the intact eye confirmed that temporal resolution was compromised under physiological conditions in vivo. The latency of responses to brief light flashes was increased $\sim 2$-fold in YF-reared flies, and information rates assessed by noise

aged across all phospholipid species) on the yeast diet (Fig. $3 C)$. Furthermore we found that our fatty acid profile of fly heads reared on normal food very closely matched that recently reported for a fraction enriched in rhabdomeric membrane (Fig. 3D; Muñoz et al., 2013). analysis of responses to naturalistic image contrast modulation were significantly impaired due to a specific reduction in the SNR at frequencies above $\sim 30 \mathrm{~Hz}$ (Fig. $5 A-D$ ). Second, we used a torque meter to record optomotor behavioral responses of intact flies in tethered flight. While yaw torque responses to 
slowly moving stimuli $\left(45^{\circ} \mathrm{s}^{-1}\right)$ were not significantly affected, responses to a fastmoving stimulus $\left(180^{\circ} \mathrm{s}^{-1}\right)$ were severely suppressed $(\sim 4$-fold) in flies reared on YF food (Fig. $5 E, F$ ). Both photoreceptor responses and optomotor behavior were restored to control levels by adding LNA to the yeast diet.

Quantum bumps are shaped by a sequence of $\mathrm{Ca}^{2+}$-dependent positive and negative feedback, which is believed to activate and inactivate the majority of channels in a single microvillus (Henderson et al., 2000). The positive feedback by $\mathrm{Ca}^{2+}$, which is highly nonlinear, could potentially compensate for and mask a more significant reduction in sensitivity of the channels to the primary activator. To explore sensitivity in the absence of $\mathrm{Ca}^{2+}$ dependent feedback, we recorded in $\mathrm{Ca}^{2+}$-free bath solution and found that sensitivity (peak amplitude to a standard intensity test flash) was now reduced $\sim 10$-fold on YF diet (Fig. $6 A, B$ ), but rescued on LNA diet. Time to peak in $\mathrm{Ca}^{2+}$ free bath was only slightly longer in flies reared on YF diet, presumably because under these conditions, the kinetics of the macroscopic response is now dominated by quantum bump lifetime ( $\sim 200 \mathrm{~ms}$ in the absence of $\mathrm{Ca}^{2+}$ influx) rather than bump latency (Henderson et al., 2000). In addition, we recorded from trp mutant flies, expressing only TRPL channels, which unlike TRP channels are not subject to $\mathrm{Ca}^{2+}$-dependent positive feedback (Reuss et al., 1997). Time to peak was once again $\sim 3 \times$ longer in trp flies reared on YF diet, and peak amplitude was now also greatly reduced $(\sim 7$-fold), with both rescued as usual by LNA added to the diet (Fig. 6C,D).

Under normal conditions, recordings in the dark are characterized by "dark noise," an ongoing barrage of miniature $(\sim 2 \mathrm{pA})$ quantum bump-like events occurring at rates of $\sim 2-4 \mathrm{~s}^{-1}$, caused by spontaneous activation of $\mathrm{G}_{\mathrm{q}^{-}}$ proteins (Hardie et al., 2002; Elia et al., 2005; Chu et al., 2013b). In fact spontaneous G-protein activations are believed to be $\sim 10 \times$ more frequent than even this, but it seems that most single activated $\mathrm{G}_{\mathrm{q}}$ l PLC complexes fail to overcome the threshold for channel activation (Katz and Minke, 2012; Chu et al., 2013b). If increasing the degree of saturation of membrane phospholipids acts either by reducing PLC activity or its downstream actions, we predicted that dark noise would be suppressed by the YF diet. Indeed, in flies reared on YF diet spontaneous dark events were greatly reduced in
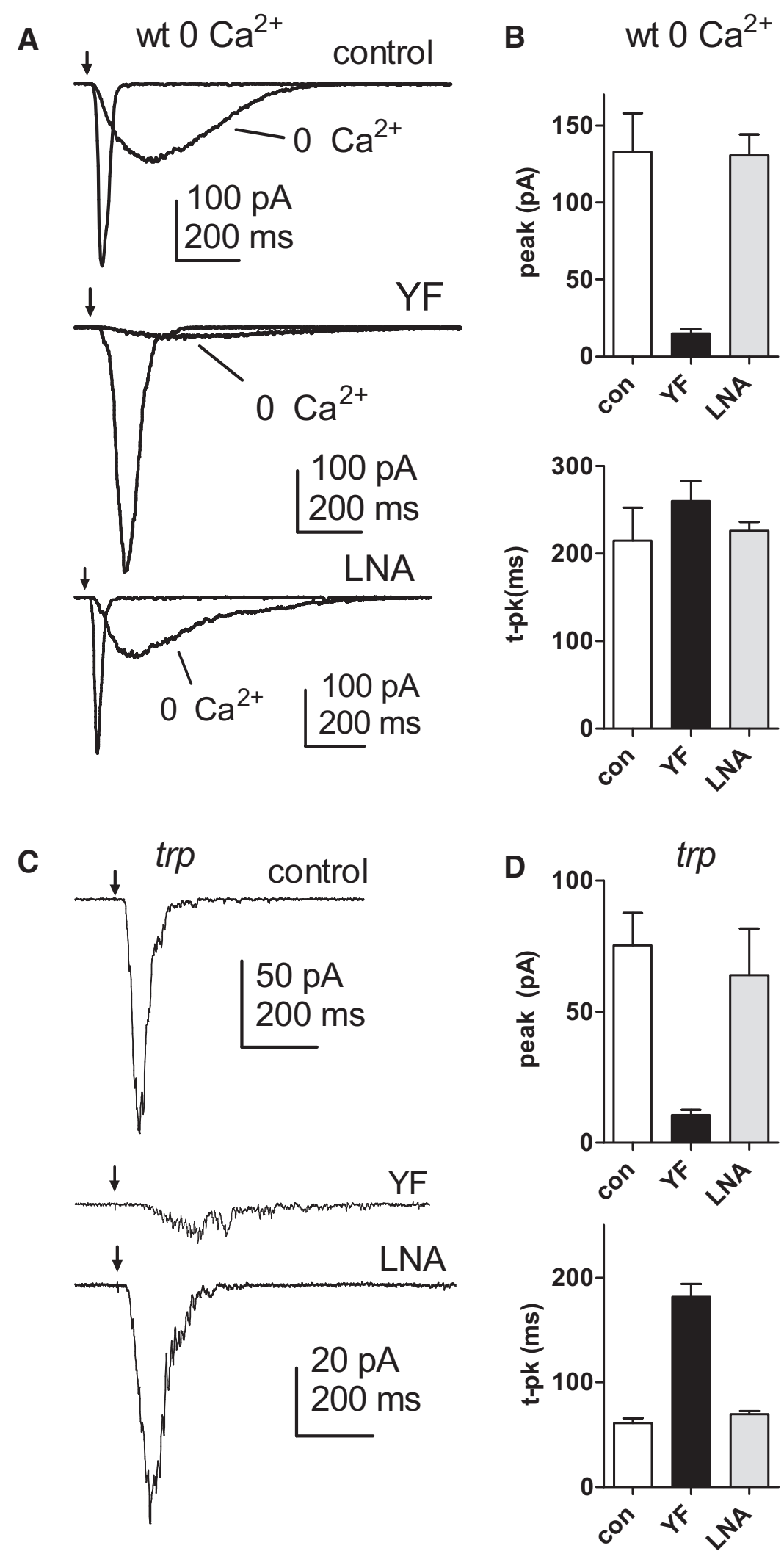

Figure 6. Effect of diet on light responses without $\mathrm{Ca}^{2+}$-dependent positive feedback. $A$, Responses to $1 \mathrm{~ms}$ flashes (arrows) containing $\sim 75$ (control and LNA) or $\sim 200$ (YF) effective photons in whole-cell, patch-clamped wild-type photoreceptors in the presence and absence of bath $\mathrm{Ca}^{2+}$. The $0 \mathrm{Ca}^{2+}$ responses in flies reared on YF diet were markedly reduced in amplitude $(p<0.0001)$, but rescued by LNA supplement to diet. $B$, Averaged peak response corrected for photon content (top) and t-pk (below) of responses in $0 \mathrm{Ca}^{2+}$ bath (mean \pm SEM; $n=8-10$ cells). C, Responses to $1 \mathrm{~ms}$ flashes (arrows) containing $\sim 75$ effective photons in $t r p^{343}$ mutant photoreceptors. Responses in flies reared on YFdiet wereslowed and reduced in amplitude $(p<0.005)$. D, Peak response (top) was $\sim 7$-fold reduced ( $p<$ 0.005 ) and t-pk (below) $\pm \sim 3$-fold slower $(p<0.0001$ ) in YF diet, but rescued by LNA supplement (mean \pm SEM; $n=8-10$ cells). 
A

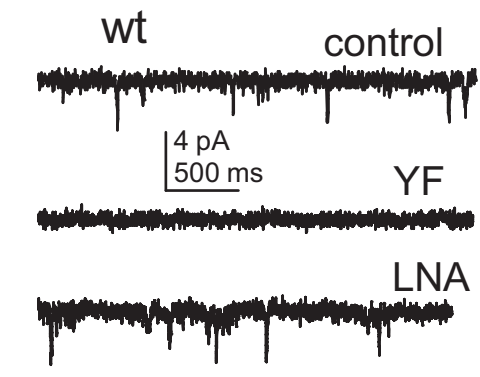

C

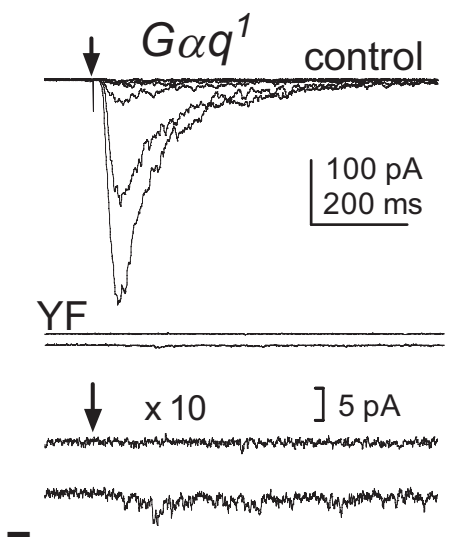

E

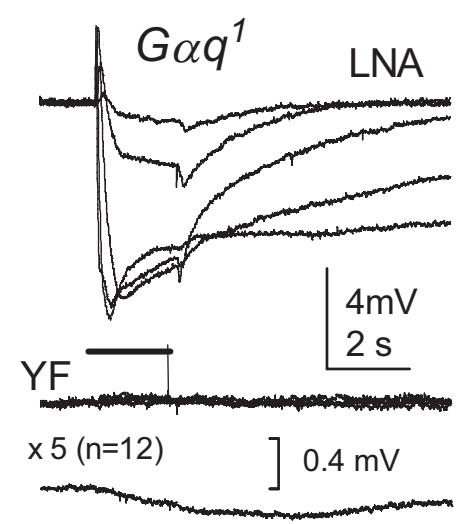

B
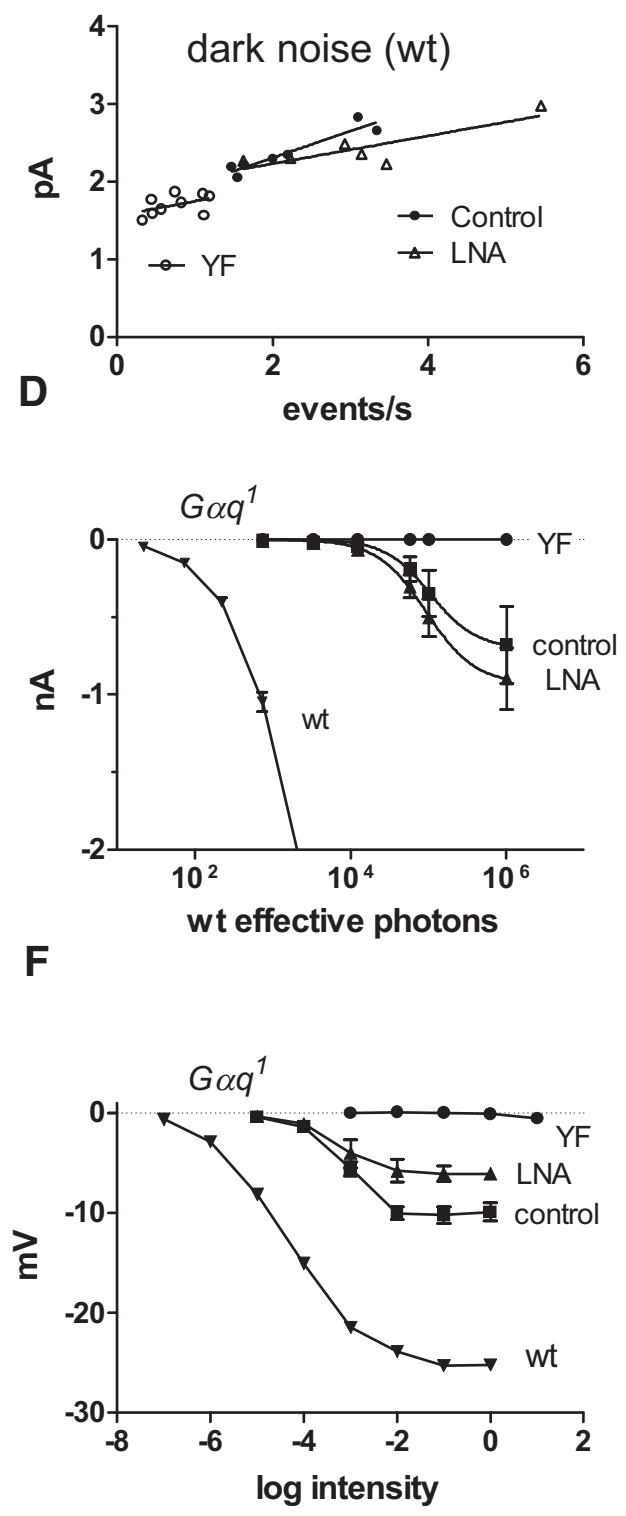

Figure 7. Suppression of dark noise and responses in Gaq mutants by YF diet. A, Whole-cell patch-clamped recordings from wild-type photoreceptors in the dark. When reared on normal diet (control) or LNA diet, spontaneous $\sim 2 \mathrm{pA}$ events occurred at $\sim 2-4$ events $^{-1}$. These were greatly suppressed on YF diet. $\boldsymbol{B}$, Scatter plot of event rate and amplitude from flies reared on YF ( $n=9$ cells), control $(n=6$ cells), and LNA diets $(n=5)$. C, Photoreceptor whole-cell recordings from $G \alpha q^{7}$ hypomorphs. Top traces, Responses from flies reared on control diet, to $10 \mathrm{~ms}$ flashes (arrows) increasing in intensity from $\sim 750$ to $10^{6}$ effective photons (wild-type calibration). Middle, Responses from two representative $G \alpha q^{7}$ cells reared on YF diet to flashes of brightest intensity ( $\sim 10^{6}$ photons) on the same scale and shown again below on $10 \times$ higher gain. One cell had no response, the other a slow $\sim 4 \mathrm{pA}$ response. $D$, Response intensity function (peak currents) from $G \alpha q^{7}$ flies reared on control diet (mean $\pm \mathrm{SEM} ; n=5$ cells), YF diet $(n=12)$, and LNA diet $(n=9)$. Data also shown for wild-type photoreceptors (LNA diet, $n=4$ ), which are $\sim 1000 \times$ more sensitive. E, ERG recordings from $G \alpha q^{1}$ hypomorphs in response to $2 \mathrm{~s}$ flashes (bar) of increasing intensity. Top traces, $G \alpha q^{1}$ fly reared on LNA diet $(\log -4$ to $\log 0)$. Middle traces, From a fly reared on YF diet ( 4 superimposed traces: $\log -3$ to $\log 0$ ). Bottom trace, Averaged response to 12 flashes of a higher intensity $(\log I=+1)$ at $5 \times$ greater gain. $F$, Response intensity function of peak ERG responses from $G \alpha q^{7}$ reared on normal (control, $n=4$ flies), YF ( $n=5)$, and LNA diets ( $n=4$ flies) compared with wt fly reared on normal food.

both frequency and amplitude, but restored by addition of LNA to the diet (Fig. $7 A, B$ ).

We also made recordings from hypomorphic $G \alpha q^{1}$ mutants where levels of $\mathrm{G}_{\mathrm{q}}$-protein $\alpha$-subunit are reduced to $\sim 1 \%$, such that each microvillus only contains one or two G-proteins at most (Scott et al., 1995). G $\alpha q^{1}$ mutants are $\sim 1000$-fold less sensitive than wild-type, due partly to smaller quantum bumps, but primarily reflecting a massive reduction in quantum efficiency. This is probably because each activated rhodopsin can, in most cases, activate only a single G-protein, and again most single G-protein/PLC complexes fail to overcome the threshold for channel activation (Scott et al., 1995; Hardie et al., 2002). Nevertheless, $G \alpha q^{1}$ mutants reared on normal food or LNA diet still generate robust responses of up to $\sim 1 \mathrm{nA}$ with sufficiently bright stimuli (Fig. 7C,D). Remarkably, rearing $G \alpha q^{1}$ flies on YF diet almost completely eliminated any response to light at all, with $6 / 12$ cells showing no detectable response to the brightest flashes tested $\left(\sim 10^{6}\right.$ effective photons). The remainder gave tiny responses $(<5$ $\mathrm{pA}$ ), consisting of a few noisy channel openings (Fig. 7C). To confirm this profound ( $>4$ orders of magnitude) loss of sensitivity in vivo, we also made electroretinogram (ERG) recordings from intact flies. $G a q^{1}$ mutants reared on normal food or LNA diet generated responses of up to 5-10 $\mathrm{mV}$ over an $\sim 4 \log$ unit dynamic range. However, in flies reared on YF diet, the response was almost entirely abolished, with at most, a tiny response of $\sim 0.2 \mathrm{mV}$ detected by averaging repeated responses to the brightest intensity (Fig. $7 E, F)$.

\section{$\mathrm{Na}^{+} / \mathrm{Ca}^{2+}$ exchange activity is not affected by diet}

The threshold for quantum bump generation is strongly dependent on the $\mathrm{Ca}^{2+}$ concentration in the microvilli (Henderson et al., 2000; Katz and Minke, 2012; Chu et al., 2013b), which in turn is largely controlled by the activity of $\mathrm{Na}^{+} / \mathrm{Ca}^{2+}$ exchanger encoded by the calX gene (Wang et al., 2005). We therefore asked whether the suppressed sensitivity on the YF diet might be due to a reduction in $\left[\mathrm{Ca}^{2+}\right]$ mediated by an increase in $\mathrm{Na}^{+} / \mathrm{Ca}^{2+}$ exchanger activity, which can be modulated by lipids such as $\mathrm{PIP}_{2}$ (Hilgemann and Ball, 1996). The $\mathrm{Na}^{+} /$ $\mathrm{Ca}^{2+}$ exchanger is electrogenic and its activity can be directly measured as an aftercurrent in response to bright light flashes (Chu et al., 2013a; Fig. 8A,B). In wild-type photoreceptors reared on normal food, this reaches a maximum of $\sim 150 \mathrm{pA}$ decaying with a characteristic time constant of $\sim 300 \mathrm{~ms}$ as the $\mathrm{Ca}^{2+}$, which entered during the light-induced TRP and TRPL current is extruded (Chu et al., 2013a). Both the amplitude and decay time constant of the $\mathrm{Na}^{+}$/ $\mathrm{Ca}^{2+}$ aftercurrent were similar in flies reared on YF diet and yeast with LNA supplement, indicating that there was no significant effect of diet on exchanger activity (Fig. 8C). 


\section{PLC activity is little altered by diet}

Other possible explanations for the effects of the YF diet include a reduction in the rate of $\mathrm{PIP}_{2}$ hydrolysis by PLC, or a reduced ability of the products or consequences of $\mathrm{PIP}_{2}$ hydrolysis to gate the channels. To distinguish these possibilities, we asked whether the rate of $\mathrm{PIP}_{2}$ hydrolysis by PLC was influenced by diet. To monitor PLC activity in real time we measured the $\mathrm{pH}$ change resulting from the PLC reaction, which releases a proton for each $\mathrm{PIP}_{2}$ hydrolyzed. As previously reported, light induces a rapid PLC-dependent acidification that can be measured with a fluorescent $\mathrm{pH}$ indicator (HPTS) loaded into the photoreceptor via the patch pipette (Huang et al., 2010). In wild-type flies, the blue excitation light used to measure HPTS fluorescence is also simultaneously a supersaturating stimulus for the cell (equivalent to $\sim 10^{9}$ effectively absorbed photons per second). To measure $\mathrm{pH}$ changes in response to less saturating illumination, we recorded HPTS fluorescence in photoreceptors from flies in which the blue-absorbing Rh1 rhodopsin had been replaced by a UV opsin (Rh3) absorbing maximally at $\sim 340 \mathrm{~nm}$ (Feiler et al., 1992; Wardill et al., 2012). In these flies, the blue excitation light now elicited only a small light-induced current, and any $\mathrm{pH}$ shift was below the limits of detection. UV light $(390 \mathrm{~nm})$ superimposed on the blue light evoked larger electrical responses and resulted in rapid reduction in HPTS fluorescence indicating acidification (Fig. 9). At these intensities (equivalent to $\sim 10^{6}-10^{7}$ effectively absorbed photons per second), the absolute rates of initial acidification between flies reared on YF or LNA were indistinguishable and there was no significant difference between any of the diets. In fact the overall $\mathrm{pH}$ shift was $\sim 2 \times$ greater in YF-reared flies, but this was because $\mathrm{pH}$ continued to fall for about twice as long in flies reared on YF (Fig. 9C). Previously we reported that PLC activity is rapidly inhibited by $\mathrm{Ca}^{2+}$ influx via PKC (Gu et al., 2005; Huang et al., 2010); hence this difference can be readily attributed to the slower onset of $\mathrm{Ca}^{2+}$-dependent inhibition of PLC due to the longer response latency in flies reared on the YF diet (Fig. 9D). Overall these results suggest that there is little if any direct effect of diet and phospholipid composition upon PLC activity.

\section{Effect of diet on photomechanical responses}

The results thus far indicate that the degree of saturation of membrane phospholipids influences the gain and kinetics of the light response downstream of PLC. Because increasing the amount of saturated phospholipids in a membrane increases its stiffness and decreases its flexibility (Brenner, 1984; Rawicz et al., 2000), this would be consistent with the hypothesis that the channels are gated mechanically, in combination with protons, as recently proposed (Hardie and Franze, 2012). We used two approaches to test whether dietary manipulation had indeed affected the photomechanical response of the photoreceptors.

First, as a "molecular force transducer," we incorporated the mechanosensitive ion channel, gramicidin (Andersen et al., 1999; Andersen and Koeppe, 2007), into membranes of photoreceptors in which native light-sensitive channel activity had been eliminated by a combination of mutation $(\operatorname{trpl})$ and pharmacological block (100 $\mu \mathrm{M} \mathrm{La}^{3+}$ and $20 \mu \mathrm{M}$ ruthenium red). Photoreceptors were loaded with gramicidin $(0.05-0.1 \mathrm{ng} / \mathrm{ml})$ via puffer pipette perfusion resulting in the gradual development of a constitutive inward current mediated by gramicidin channels (Fig. 10A). Before the addition of gramicidin, bright test flashes under these conditions only elicited a tiny biphasic current (Fig. 10B), which may represent the electrical signature of the charge displacement as negatively charged $\mathrm{InsP}_{3}$ is released from the membrane by PLC (Huang et al., 2010). As previously reported (Hardie and Franze, 2012), after incorporation of gramicidin channels into the membrane, the same test flash $\left(\sim 10^{5}\right.$ effective photons $)$ elicited, in addition, a rapid 15-20\% increase in the gramicidinmediated inward current, which we attribute to the change in the physical properties of the bilayer upon $\mathrm{PIP}_{2}$ hydrolysis. Lightelicited gramicidin responses in flies reared on normal diet and LNA diets were indistinguishable and could be well fitted by a single exponential with a time constant of $\sim 250 \mathrm{~ms}$ (Fig. $10 B-D)$. However, in flies reared on YF diet, the responses were $\sim 2$-fold slower (tau $\sim 500 \mathrm{~ms}$ ). Responses on YF diet also tended to be slightly larger in amplitude, but this did not reach statistical significance ( $p=0.12$, one-way ANOVA).

In a second approach, we also directly measured light-induced contractions of retinas in flies reared on different diets using atomic force microscopy (Franze, 2011; Hardie and Franze, 
A
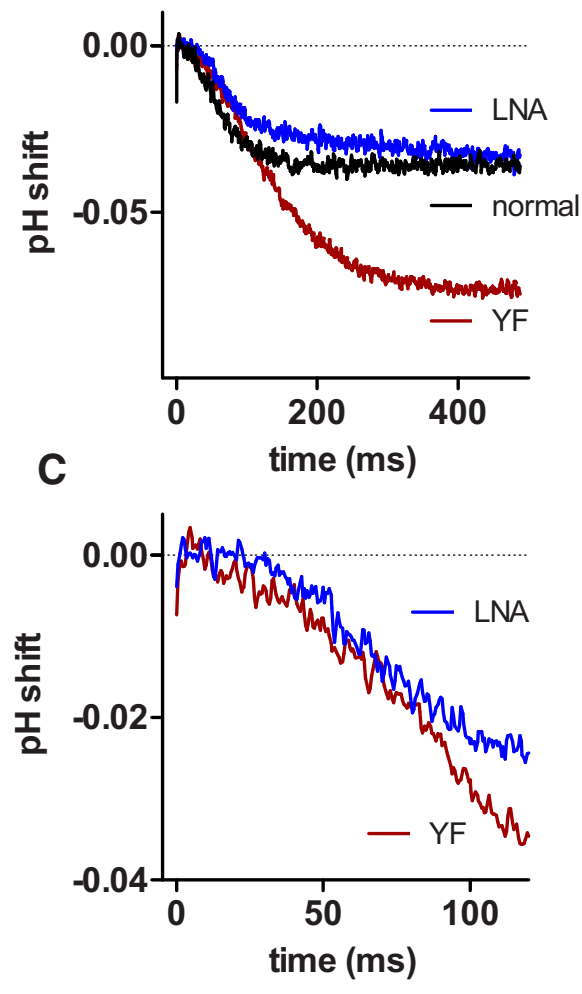

B
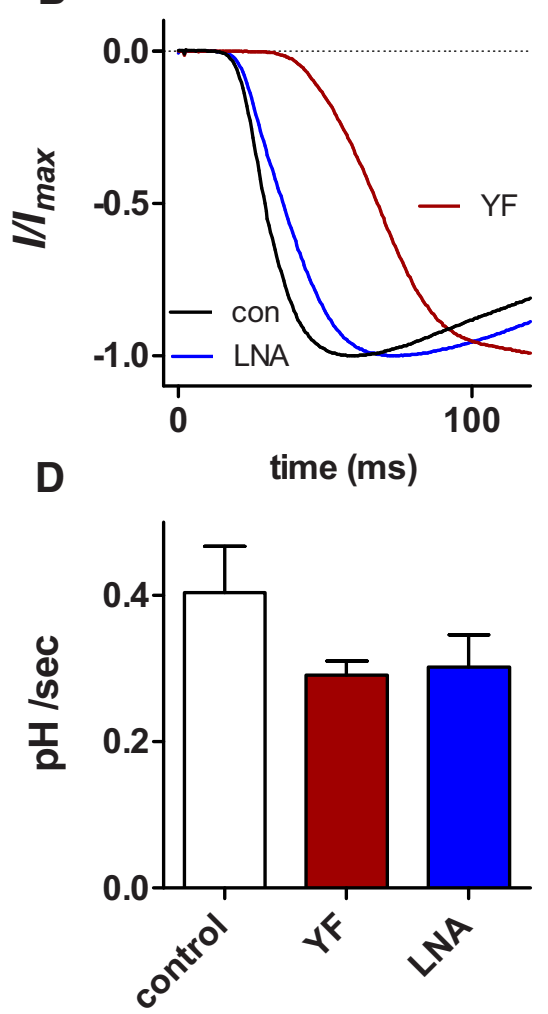

Figure 9. PLC activity is unaffected by diet. $\boldsymbol{A}$, pH shift derived from HPTS fluorescence measured in whole-cell patchclamped $p[R h 3]$, nina $E^{8}$ photoreceptors in response to illumination $(390 \mathrm{~nm}$ ultrabright UV LED superimposed with blue excitation: effective intensity $\sim 5 \times 10^{6}$ photons/s). The rate of initial acidification was similar in flies reared on all diets. In YF-reared flies, the fall in $\mathrm{pH}$ was prolonged and larger, attributable to the delayed $\mathrm{Ca}^{2+}$ influx, and hence delayed inhibition of PLC. $B$, Simultaneously recorded currents on YF and LNA diets, normalized to emphasize the slower response on YF diet. Each trace $(\boldsymbol{A}, \boldsymbol{B})$ is the average of responses from seven (LNA and control) or nine cells (YF). $\boldsymbol{C}$, pH shift for YF and LNA flies plotted on faster timescale. $\boldsymbol{D}$, Rate of initial pH shift (mean \pm SEM, slope of straight line fit between 30 and 80 $\mathrm{ms}$ ) in $\mathrm{pH}$ units per second. There was no significant difference between flies reared on any of the diets (one-way ANOVA). The tendency for a steeper slope in control flies, if real, is likely explained by slightly higher visual pigment concentration (and hence higher effective intensity).

2012). Experiments were again performed on $\operatorname{trpl}$ mutants expressing only TRP channels, because it is then possible to completely block all light-sensitive channel activity by perfusion with $\mathrm{La}^{3+}$ (see below). As previously described, brief light flashes evoked rapid contractions of the photoreceptors, which we interpret as a narrowing of the microvillar diameters when $\mathrm{PIP}_{2}$ is hydrolyzed from the inner leaflet of the lipid bilayer (Hardie and Franze, 2012). The maximum contractions evoked in flies reared on YF diet tended to be slightly larger than on normal or LNA diets, but also peaked later (time to peak $172 \pm 31 \mathrm{~ms}$, cf. $131 \pm$ $10.5 \mathrm{~ms}$ on control food and $119 \pm 25.6 \mathrm{~ms}$ on LNA diet). This can again be interpreted in terms of the delayed onset in the $\mathrm{Ca}^{2+}$ influx required to terminate PLC activity in flies reared on YF diet. Significantly however, and in contrast to PLC activity itself (Fig. 9), the contractions elicited from retinas of flies reared on YF diet were consistently up to $\sim 2$-fold slower than in flies reared on normal food or yeast with LNA supplement (Fig. 11). To avoid feedback effects due to $\mathrm{Ca}^{2+}$ influx, we also made measurements from trpl retinas after perfusion with $\mathrm{La}^{3+}(100 \mu \mathrm{M})$ and ruthenium red $(10 \mu \mathrm{M})$ to block all lightsensitive TRP channel activity. As previously reported (Hardie and Franze, 2012), the magnitude of the contractions was enhanced (because of the now total lack of $\mathrm{Ca}^{2+}$-dependent inhibition of PLC), but once again contractions recorded in retinas from flies reared on YF diet were consistently slower (Fig. $11 \mathrm{C}, F$ ).

Although there is not an exact correspondence in the kinetics of the gramicidin and AFM responses, each is subject to additional constraints. Gramicidin responses also reflect the relatively slow gating kinetics of channel activation, which requires association of two hemichannels (one in each leaflet). The photomechanical responses are presumed to derive from contractions of the microvilli (where the light-sensitive channels are located), but because the AFM probe can only be positioned on the distal ends of ommatidia, the measurements will inevitably be filtered by the viscoelastic properties of the photoreceptor and retinal tissue.

\section{Discussion}

The ability to manipulate fatty acid composition of phospholipids in flies by diet has been reported previously (Zinkler et al., 1985; Stark et al., 1993; Shen et al., 2010; Carvalho et al., 2012). However, to our knowledge, there are no convincing reports of physiological consequences. Here, we found that the proportion of polyunsaturated phospholipids in flies reared on yeast was reduced $\sim 7$-fold (Fig. 3 ), and that this was associated with pronounced effects on visual performance, with photoreceptor responses slowed 2to 3-fold, without significantly affecting quantum bump waveform, $\mathrm{Na}^{+} / \mathrm{Ca}^{2+}$ exchange, or PLC activity. Although absolute sensitivity was little affected by diet in wild-type photoreceptors, this could be attributed to compensation by $\mathrm{Ca}^{2+}$-dependent positive feedback acting on TRP channels. In the absence of $\mathrm{Ca}^{2+}$ influx or in $\operatorname{trp}$ mutants expressing only TRPL channels, sensitivity was reduced up to $\sim 10$-fold, and essentially abolished in hypomorphic $G \alpha q^{1}$ mutants. Our results indicate that these effects, all of which were rescued by the addition of a single species of PUFA to the yeast diet, were mediated predominantly downstream of PLC and were associated with slowing of photomechanical responses.

\section{Mechanism of activation}

The macroscopic light response in Drosophila reflects the summation of quantum bumps, each arising from activation of most of the $\sim 20$ TRP channels in a single microvillus. Briefly, a single activated rhodopsin is believed to activate $\sim 5$ or so $\mathrm{G}_{\mathrm{q}}$-proteins by random diffusional encounters, and each released $G_{\mathrm{q}}$ $\alpha$-subunit diffuses further before binding and activating PLC. Each PLC molecule rapidly hydrolyzes $\mathrm{PIP}_{2}$, building up sufficient excitatory "messenger" to overcome a finite threshold required to activate the first TRP channel with a stochastically variable latency of $\sim 15-100 \mathrm{~ms}$. The resulting $\mathrm{Ca}^{2+}$ influx raises $\mathrm{Ca}^{2+}$ throughout the microvillus into the micromolar range within milliseconds, facilitating activation of the remaining channels, and generating an "all-or-none" quantum bump local- 
ized to a single microvillus. This raises $\mathrm{Ca}^{2+}$ within the affected microvillus to $\sim 1 \mathrm{~mm}$, terminating the bump by $\mathrm{Ca}^{2+}$ dependent inactivation of the channels and preceding steps of the cascade (for reviews and computational models see Postma et al., 1999; Pumir et al., 2008; Hardie, 2012; Song et al., 2012). This highly nonlinear positive and negative feedback cycle, which shapes the quantum bump waveform, was apparently not influenced by diet (Fig. 4E,H). However, bump latency, i.e., the time taken to activate the first channel, was clearly profoundly delayed in flies reared on the YF $\operatorname{diet}$ (Fig. 4D, F, G).

Which products of PLC activity are responsible for this initial gating remains controversial. $\mathrm{InsP}_{3}$ and $\mathrm{Ca}^{2+}$ stores apparently play no role, because mutants of the $\mathrm{InsP}_{3}$ receptor have normal phototransduction (Acharya et al., 1997; Raghu et al., 2000). Alternative candidates include DAG or PUFAs, which might be released from DAG by an appropriate lipase. Of these, DAG has generally proved ineffective as an agonist when exogenously applied; however, there is genetic evidence, based on mutants of DAG kinase $(r d g A)$, for DAG as an excitatory messenger (for review, see Raghu and Hardie, 2009; Hardie, 2012). One lab has also reported that DAG can activate TRP channels in excised patches from dissociated rhabdomeres (Delgado and Bacigalupo, 2009; Delgado et al., 2014); however, activation was very sluggish with delays of up to $60 \mathrm{~s}$, in a preparation that is in a physiologically severely compromised state.

In contrast, there is universal consensus that PUFAs are very effective agonists when exogenously applied to both native channels in the photoreceptors and heterologously expressed TRPL channels. Apparent support for endogenous PUFAs came from the reduced light response found in a Drosophila DAG lipase mutant, inaE (Leung et al., 2008). However, inaE encodes an sn-1 DAG lipase, which rather than PUFAs, releases mono-acyl glycerols (MAGs), which are at best weak and slowly acting channel agonists when applied exogenously (Hardie, unpublished results). For PUFA generation, either an $s n-2$ DAG lipase or an additional enzyme (MAG lipase) would be required, but there is no evidence for either in photoreceptors. Furthermore, the inaE gene product immunolocalizes to the cell body with, at most, occasional puncta in the rhabdomere (Leung et al., 2008), and there is no evidence that PUFAs are generated in response to illumination (Delgado et al., 2014).

An alternative hypothesis comes from evidence showing that the channels can be activated by the strict combination of two further consequences of PLC action, namely $\mathrm{PIP}_{2}$ depletion and proton release (Huang et al., 2010). Furthermore it was suggested
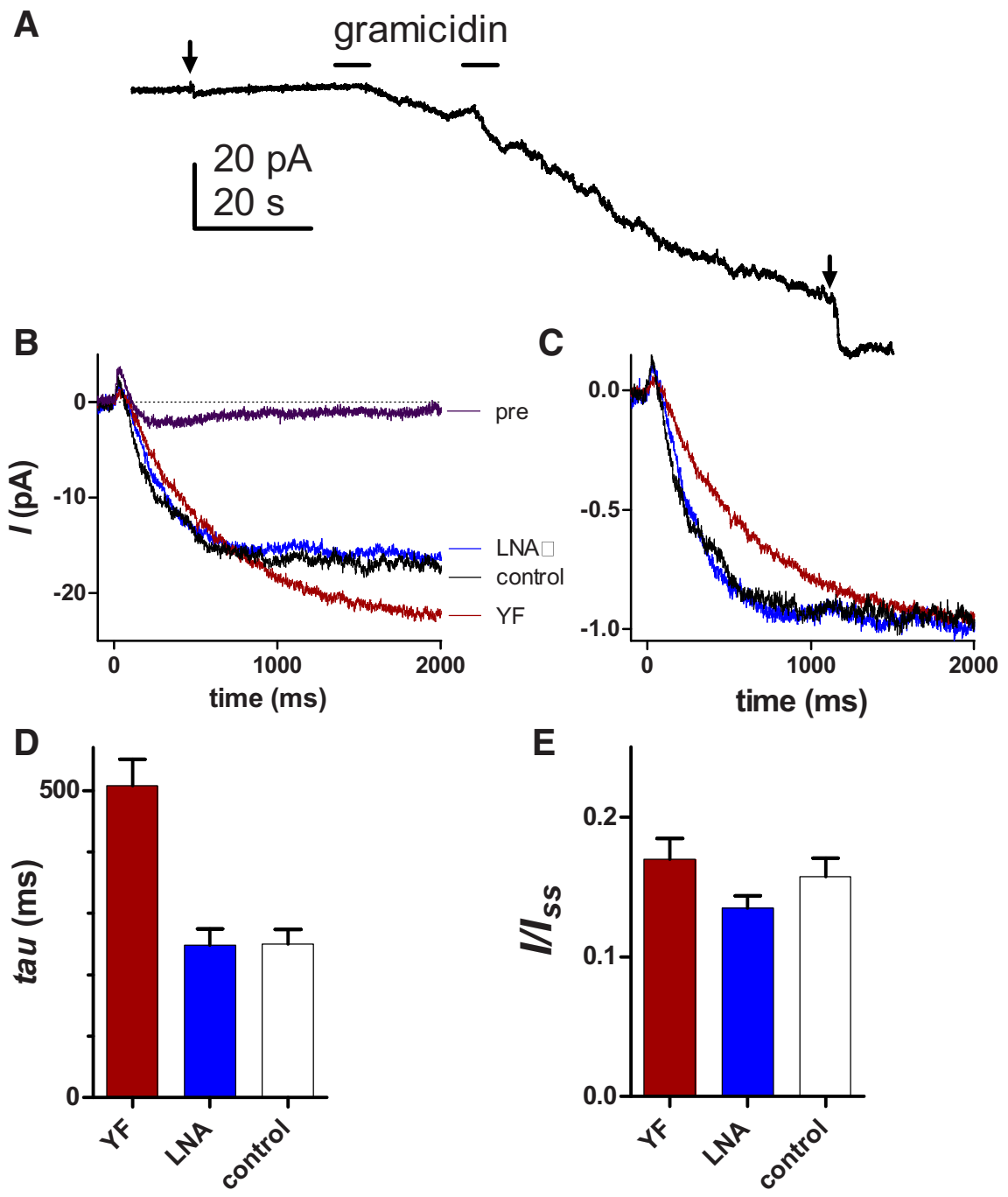

Figure 10. Responses mediated by mechanosensitive gramicidin channels. $A$, Representative whole-cell recording from a trp/ mutant (reared on LNA diet) in bath containing $\mathrm{La}^{3+}(100 \mu \mathrm{M})$ and ruthenium red $(20 \mu \mathrm{M})$ to ensure total blockade of the light-sensitive TRP channels. A $10 \mathrm{~ms}$ test flash ( $\sim 10^{5}$ effective photons, arrowhead) elicited a tiny residual biphasic current (see B). Two brief ( $4 \mathrm{~s}$ bars) applications of gramicidin $(0.1 \mathrm{ng} / \mathrm{ml}$ ) from a puffer pipette resulted in an inward current as NA diets; residual response $(n=9)$ before gramicidin application (pre) shown for comparison. C, Same responses normalized to mphasize difference in kinetics. $\boldsymbol{D}$, Time constants (tau) of single exponentials fitted to the responses were $\sim 2 \times$ slower in flies raised on YF diet (mean \pm SEM; $n=9-14$ cells: $p<0.001$, one-way ANOVA, Bonferroni correction). $E$, Amplitudes of responses expressed as fraction of the steady-state gramicidin current $\left(I_{s S}\right)$ were not significantly different.

that $\mathrm{PIP}_{2}$ 's role is mediated not by ligand binding/unbinding but by the physical effects of $\mathrm{PIP}_{2}$ depletion on the lipid bilayer (Hardie and Franze, 2012). Thus, removal of $\mathrm{PIP}_{2}$ 's inositol headgroup from the inner leaflet effectively reduces membrane area, and it was proposed that the resulting mechanical effects (on, e.g., membrane tension, curvature, or lateral pressure) lead to mechanical gating of the channels, in combination with protons. Evidence supporting this included: (1) the ability of light to activate ectopic mechanosensitive channels (gramicidin); (2) facilitation of light responses by hypotonic solutions; and (3) rapid contractions of the photoreceptors in response to light, interpreted as the concerted contraction of microvilli due to $\mathrm{PIP}_{2}$ hydrolysis in the inner leaflet (Hardie and Franze, 2012).

In the present study we used diet to increase the degree of saturation of the phospholipids, which should make membranes 


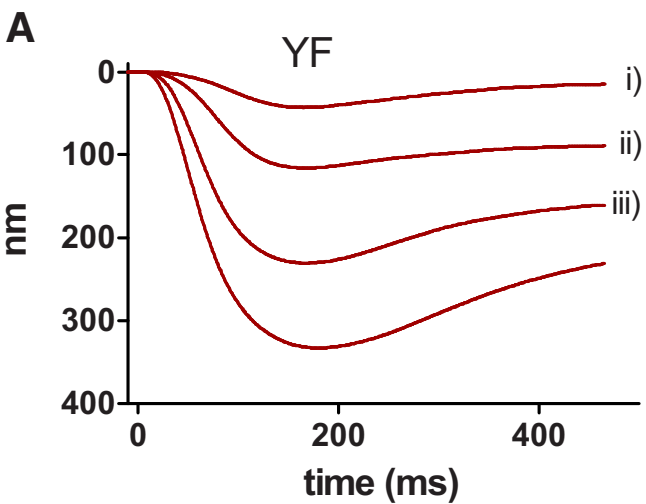

B

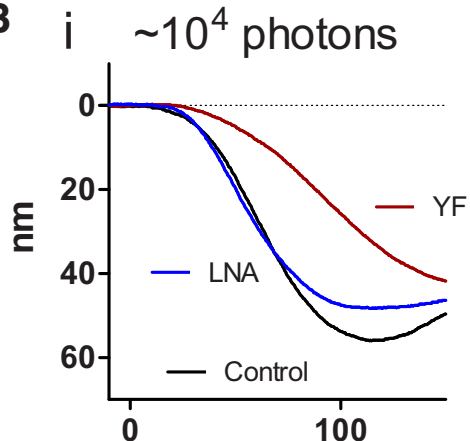

C
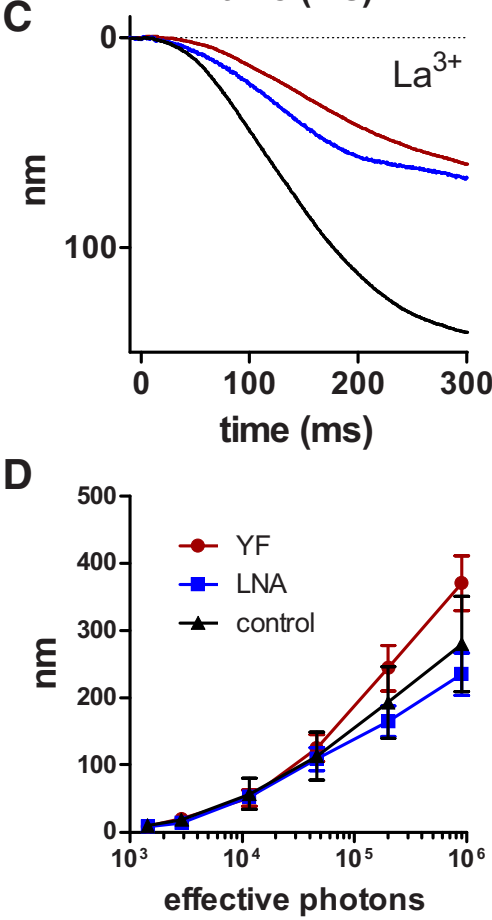

ii $\quad 4 \times 10^{4}$

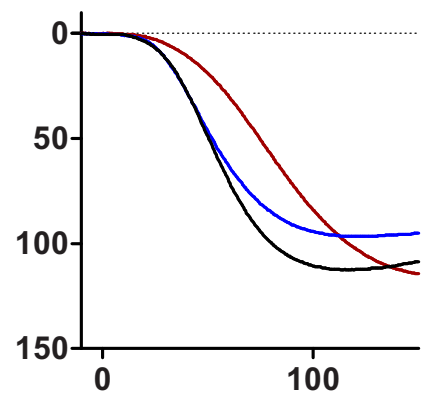

time (ms)

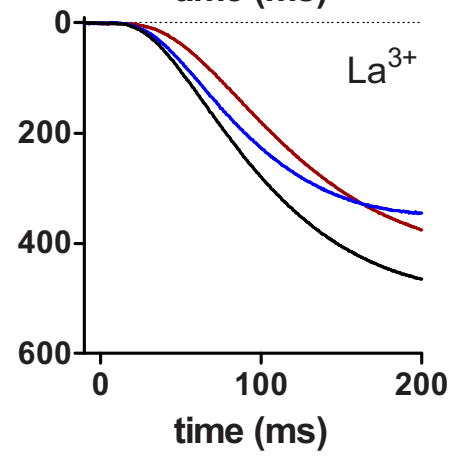

E

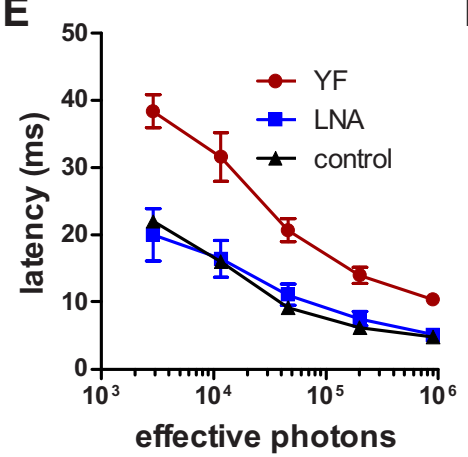

LNA \& control

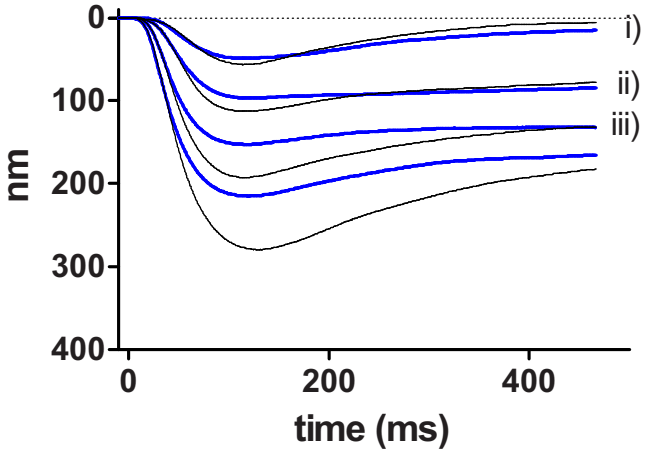

iii $2 \times 10^{5}$

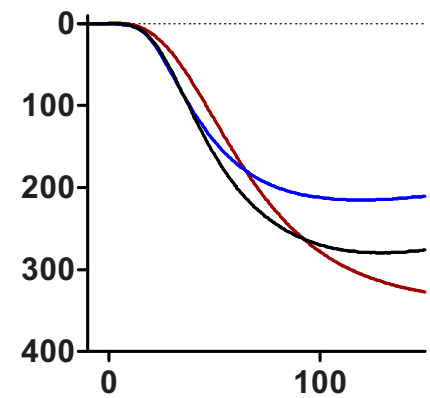

time (ms)

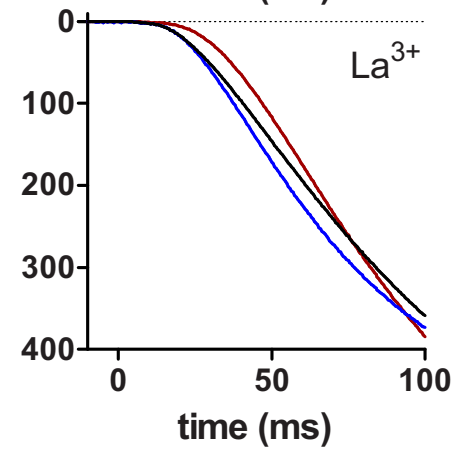

$\mathbf{F}$

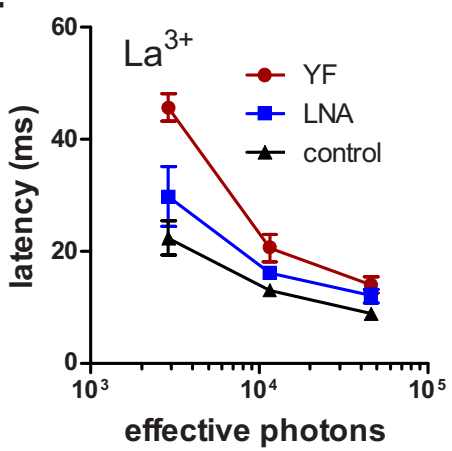

Figure 11. AFM measurements of light-induced contractions. $A$, AFM responses (contractions in nanometers) to 2 ms flashes of increasing intensity $\left(\sim 10^{4}-10^{6}\right.$ effective photons, delivered at $\left.t=0\right)$ in retinas dissected from trp/mutant flies: left, reared on YF diet (traces averaged from $n=8$ retinas); right, on LNA (blue traces, $n=9$ ) and control diets (black traces, $n=9$ ). $\boldsymbol{B}$, Comparison of contractions elicited at three different intensities $\left(10^{4}, 4 \times 10^{4}\right.$, and $2 \times 10^{5}$ effective photons) on the three diets (traces $\mathrm{i}-$ iii from $\boldsymbol{A}$ on faster time bases). In all cases retinas from flies reared on YF diet gave slower contractions. C, Responses to the same intensity flashes after completeblock of light-sensitive channels with La ${ }^{3+}(100 \mu \mathrm{m})$ and ruthenium red (RR; $\left.10 \mu \mathrm{m}\right)$. The contractions in YFflies ( $\left.n=10\right)$ were again slower than control $(n=5)$ and LNA-reared flies $(n=7)$. $\boldsymbol{D}$, Response intensity function (mean \pm SEM. of maximum contractions plotted against effective intensity). $\boldsymbol{E}$, Latency to first detectable contraction as a function of intensity in flies reared on different diets in normal bath solution. $\boldsymbol{F}$, Latency measured from contractions after channel block by La ${ }^{3+}$ and RR.

stiffer and less flexible (Brenner, 1984; Rawicz et al., 2000), and we predicted that this might suppress mechanosensitive channel activity. Lipidomic analysis confirmed a drastic sevenfold reduction in PUFA content across all phospholipid species in YF- reared flies. This was associated with a 2- to 3-fold longer latency and a marked reduction in open probability once $\mathrm{Ca}^{2+}$ dependent positive feedback was eliminated (Figs. 4, 6). In principle PLC activity might be suppressed by the YF diet, because 
membrane fluidity, and hence diffusion (e.g., of G-proteins, or $\mathrm{PIP}_{2}$ ), might be slower in a membrane dominated by saturated phospholipids. However, molecular dynamic simulations predict that lateral diffusion coefficients in fact depend only weakly on the degree of phospholipid saturation (Ollila et al., 2007). Importantly, the rate of PIP $_{2}$ hydrolysis monitored by proton release appeared unaffected by diet (Fig. 9) suggesting that diet was acting primarily downstream of PLC. That dietary manipulation had indeed resulted in alteration to the mechanical properties of the membrane was supported by AFM measurements of the light-induced contractions and responses mediated by ectopic mechanosensitive gramicidin channels. These indicated that, despite the lack of effect on PLC activity, YF-reared flies generated slower photomechanical responses

Although consistent with the mechanical gating hypothesis, by themselves our data do not exclude the alternative suggestions, that the excitatory messenger is DAG or a PUFA. According to a recent study (Delgado et al., 2014), DAG generated by light-induced $\mathrm{PIP}_{2}$ hydrolysis in Drosophila photoreceptor membrane includes both monounsaturated and polyunsaturated species (32:1, 32:2, 34:1, 34:2, 36:3, and 36:4) suggesting at least some derive from polyunsaturated $\mathrm{PIP}_{2}$ species. In turn, should any fatty acids be released from DAG, they would most likely include PUFAs. However, the near absence of polyunsaturated $\mathrm{PIP}_{2}$ in flies reared on YF diets (Fig. 2) implies that DAG generated in response to light would now be predominantly saturated or monounsaturated. If different species of DAG and/or PUFA had different potencies for activating the channels, then in principle this might also explain our results. In this respect, the otherwise equivocal evidence for DAG and PUFAs as messengers notwithstanding, it should be noted that heterologously expressed TRPL channels are activated more potently by linolenic than by oleic acid (Chyb et al., 1999) and that polyunsaturated DAG species have been reported to be more effective activators of PKC in mammalian cells (Pettitt et al., 1997; Pettitt and Wakelam, 1999).

In conclusion, our results confirm that fatty acid composition of phospholipids is strongly influenced by diet in Drosophila. Increasing the degree of saturation leads to pronounced slowing of the electrical light response, which is associated with slower photomechanical responses. These findings are consistent with the suggestion that TRP and TRPL channel activation in Drosophila photoreceptors are mediated, together with protons, by mechanical forces in the membrane induced by $\mathrm{PIP}_{2}$ hydrolysis by PLC. To what extent visual performance in flies might be affected by dietary fatty acids under natural conditions is unknown. Although Drosophila thrive on a yeast diet in the laboratory, their typical food is rotting plant material, which will contain PUFAs to varying degrees. Interestingly, in food-preference studies, Drosophila larvae show preference for unsaturated over saturated fatty acids, but this preference is reversed in adult flies (Fougeron et al., 2011). The fatty acid composition of mammalian phospholipids is also influenced by diet, and the effects of fatty acid intake on health and disease are extensively documented. Certain PUFAs such as $\omega$-3 (e.g., $\alpha$-linolenic acid) and $\omega$-6 (e.g., linoleic acid) can only be supplied by dietary intake in mammals. Of these, $\alpha$-linolenic acid is also precursor for docosahexaenoic acid (22:6), which is the most abundant $\omega-3$ fatty acid in mammalian brain and retina (though absent in flies). $\omega-3$ and $\omega-6$ deficiency is associated with cardiovascular disease and diabetes, can lead to cognitive defects in rodents, and within the mammalian retina leads to a reduced a-wave in the ERG (Benolken et al., 1973; Organisciak and Vaughan, 2010; Jump et al., 2012; Weijers, 2012). However, the un- derlying mechanisms are poorly understood, and in this respect, our results provide a striking and novel example of how dietary fatty acids can profoundly and specifically influence in vivo performance and behavior via a defined step within the context of a classical G-protein-coupled signaling cascade. Interestingly, the importance of the mechanical properties of membranes containing polyunsaturated phospholipids has also been highlighted in recent studies of mechanosensation (Vásquez et al., 2014) and rapid endocytosis (Pinot et al., 2014).

\section{References}

Acharya JK, Jalink K, Hardy RW, Hartenstein V, Zuker CS (1997) InsP receptor is essential for growth and differentiation but not for vision in Drosophila. Neuron 18:881-887. CrossRef Medline

Andersen OS, Koeppe RE 2nd (2007) Bilayer thickness and membrane protein function: an energetic perspective. Annu Rev Biophys Biomol Struct 36:107-130. CrossRef Medline

Andersen OS, Nielsen C, Maer AM, Lundbaek JA, Goulian M, Koeppe RE 2nd (1999) Ion channels as tools to monitor lipid bilayer-membrane protein interactions: gramicidin channels as molecular force transducers. Methods Enzymol 294:208-224. CrossRef Medline

Belusic G, Pirih P, Stavenga DG (2010) Photoreceptor responses of fruitflies with normal and reduced arrestin content studied by simultaneous measurements of visual pigment fluorescence and ERG. J Comp Physiol A Neuroethol Sens Neural Behav Physiol 196:23-35. CrossRef Medline

Benolken RM, Anderson RE, Wheeler TG (1973) Membrane fatty acids associated with the electrical response in visual excitation. Science 182: 1253-1254. CrossRef Medline

Brenner RR (1984) Effect of unsaturated acids on membrane structure and enzyme kinetics. Prog Lipid Res 23:69-96. CrossRef Medline

Carvalho M, Sampaio JL, Palm W, Brankatschk M, Eaton S, Shevchenko A (2012) Effects of diet and development on the Drosophila lipidome. Mol Syst Biol 8:600. CrossRef Medline

Chu B, Postma M, Hardie RC (2013a) Fractional $\mathrm{Ca}^{2+}$ Currents through TRP and TRPL Channels in Drosophila Photoreceptors. Biophys J 104: 1905-1916. CrossRef Medline

Chu B, Liu CH, Sengupta S, Gupta A, Raghu P, Hardie RC (2013b) Common mechanisms regulating dark noise and quantum bump amplification in Drosophila photoreceptors. J Neurophysiol 109:2044-2055. CrossRef Medline

Chyb S, Raghu P, Hardie RC (1999) Polyunsaturated fatty acids activate the Drosophila light-sensitive channels TRP and TRPL. Nature 397:255-259. CrossRef Medline

Clark J, Anderson KE, Juvin V, Smith TS, Karpe F, Wakelam MJ, Stephens LR, Hawkins PT (2011) Quantification of PtdInsP3 molecular species in cells and tissues by mass spectrometry. Nat Methods 8:267-272. CrossRef Medline

Delgado R, Bacigalupo J (2009) Unitary recordings of TRP and TRPL channels from isolated Drosophila retinal photoreceptor rhabdomeres: activation by light and lipids. J Neurophysiol 101:2372-2379. CrossRef Medline

Delgado R, Muñoz Y, Peña-Cortés H, Giavalisco P, Bacigalupo J (2014) Diacylglycerol activates the light-dependent channel TRP in the photosensitive microvilli of Drosophila melanogaster photoreceptors. J Neurosci 34:6679-6686. CrossRef Medline

Ejsing CS, Sampaio JL, Surendranath V, Duchoslav E, Ekroos K, Klemm RW, Simons K, Shevchenko A (2009) Global analysis of the yeast lipidome by quantitative shotgun mass spectrometry. Proc Natl Acad Sci U S A 106 : 2136-2141. CrossRef Medline

Elia N, Frechter S, Gedi Y, Minke B, Selinger Z (2005) Excess of G\{beta\}e over Gq\{alpha\} in vivo prevents dark, spontaneous activity of Drosophila photoreceptors. J Cell Biol 171:517-526. CrossRef Medline

Fain GL, Hardie R, Laughlin SB (2010) Phototransduction and the evolution of photoreceptors. Curr Biol 20:R114-R124. CrossRef Medline

Feiler R, Bjornson R, Kirschfeld K, Mismer D, Rubin GM, Smith DP, Socolich M, Zuker CS (1992) Ectopic expression of ultraviolet-rhodopsins in the blue photoreceptor cells of Drosophila: visual physiology and photochemistry of transgenic animals. J Neurosci 12:3862-3868. Medline

Fougeron AS, Farine JP, Flaven-Pouchon J, Everaerts C, Ferveur JF (2011) Fatty-acid preference changes during development in Drosophila melanogaster. PLoS One 6:e26899. CrossRef Medline

Franze K (2011) Atomic force microscopy and its contribution to under- 
standing the development of the nervous system. Curr Opin Genet Dev 21:530-537. CrossRef Medline

Gu Y, Oberwinkler J, Postma M, Hardie RC (2005) Mechanisms of light adaptation in Drosophila photoreceptors. Curr Biol 15:1228-1234. CrossRef Medline

Hardie RC (2011) A brief history of trp: commentary and personal perspective. Pflugers Arch 461:493-498. CrossRef Medline

Hardie RC (2012) Phototransduction mechanisms in Drosophila microvillar photoreceptors. WIREs Membr Transp Signal 1:162-187. CrossRef

Hardie RC, Franze K (2012) Photomechanical responses in Drosophila photoreceptors. Science 338:260-263. CrossRef Medline

Hardie RC, Minke B (1992) The trp gene is essential for a light-activated $\mathrm{Ca}^{2+}$ channel in Drosophila photoreceptors. Neuron 8:643-651. CrossRef Medline

Hardie RC, Martin F, Cochrane GW, Juusola M, Georgiev P, Raghu P (2002) Molecular basis of amplification in Drosophila phototransduction. Roles for $\mathrm{G}$ protein, phospholipase $\mathrm{C}$, and diacylglycerol kinase. Neuron 36: 689-701. CrossRef Medline

Henderson SR, Reuss H, Hardie RC (2000) Single photon responses in Drosophila photoreceptors and their regulation by $\mathrm{Ca}^{2+}$. J Physiol 524:179194. CrossRef Medline

Hilgemann DW, Ball R (1996) Regulation of cardiac $\mathrm{Na}^{+}, \mathrm{Ca}^{2+}$ exchange and KATP potassium channels by PIP $_{2}$. Science 273:956-959. CrossRef Medline

Huang J, Liu CH, Hughes SA, Postma M, Schwiening CJ, Hardie RC (2010) Activation of TRP channels by protons and phosphoinositide depletion in Drosophila photoreceptors. Curr Biol 20:189-197. CrossRef Medline

Isono K, Tanimura T, Oda Y, Tsukahara Y (1988) Dependency on light and vitamin A derivatives of the biogenesis of 3-hydroxyretinal and visual pigment in the compound eyes of Drosophila melanogaster. J Gen Physiol 92:587-600. CrossRef Medline

Jump DB, Depner CM, Tripathy S (2012) Omega-3 fatty acid supplementation and cardiovascular disease. J Lipid Res 53:2525-2545. CrossRef Medline

Juusola M, de Polavieja GG (2003) The rate of information transfer of naturalistic stimulation by graded potentials. J Gen Physiol 122:191-206. CrossRef Medline

Juusola M, Hardie RC (2001) Light adaptation in Drosophila photoreceptors: I. Response dynamics and signaling efficiency at $25^{\circ} \mathrm{C}$. J Gen Physiol 117:3-25. CrossRef Medline

Juusola M, Kouvalainen E, Järvilehto M, Weckström M (1994) Contrast gain, signal-to-noise ratio, and linearity in light-adapted blowfly photoreceptors. J Gen Physiol 104:593-621. CrossRef Medline

Katz B, Minke B (2009) Drosophila photoreceptors and signaling mechanisms. Front Cell Neurosci 3:2. CrossRef Medline

Katz B, Minke B (2012) Phospholipase C-mediated suppression of dark noise enables single-photon detection in Drosophila photoreceptors. J Neurosci 32:2722-2733. CrossRef Medline

Leung HT, Tseng-Crank J, Kim E, Mahapatra C, Shino S, Zhou Y, An L, Doerge RW, Pak WL (2008) DAG lipase activity is necessary for TRP channel regulation in Drosophila photoreceptors. Neuron 58:884-896. CrossRef Medline

Lev S, Katz B, Tzarfaty V, Minke B (2012) Signal-dependent hydrolysis of phosphatidylinositol 4,5-bisphosphate without activation of phospholipase C: implications on gating of Drosophila TRPL (transient receptor potential-like) channel. J Biol Chem 287:1436-1447. CrossRef Medline

Matsumoto H, O'Tousa JE, Pak WL (1982) Light-induced modification of Drosophila retinal polypeptides in vivo. Science 217:839-841. CrossRef Medline

Minke B, Kirschfeld K (1979) The contribution of a sensitizing pigment to the photosensitivity spectra of fly rhodopsin and metarhodopsin. J Gen Physiol 73:517-540. CrossRef Medline

Montell C (2012) Drosophila visual transduction. Trends Neurosci 35:356363. CrossRef Medline

Montell C, Rubin GM (1989) Molecular characterization of Drosophila trp locus, a putative integral membrane protein required for phototransduction. Neuron 2:1313-1323. CrossRef Medline

Muñoz Y, Fuenzalida K, Bronfman M, Gatica A, Sepúlveda M, JB, Bacigalupo J, Roth AD, Delgado R (2013) Fatty acid composition of Drosophila photoreceptor light-sensitive microvilli. Biol Res 46:289-294. CrossRef Medline

Niemeyer BA, Suzuki E, Scott K, Jalink K, Zuker CS (1996) The Drosophila light-activated conductance is composed of the two channels TRP and TRPL. Cell 85:651-659. CrossRef Medline

Norton LJ, Zhang Q, Saqib KM, Schrewe H, Macura K, Anderson KE, Lindsley CW, Brown HA, Rudge SA, Wakelam MJ (2011) PLD1 rather than PLD2 regulates phorbol-ester, adhesion-dependent and Fc\{gamma $\}$ receptor-stimulated ROS production in neutrophils. J Cell Sci 124:19731983. CrossRef Medline

Ollila S, Hyvönen MT, Vattulainen I (2007) Polyunsaturation in lipid membranes: dynamic properties and lateral pressure profiles. J Phys Chem B 111:3139-3150. CrossRef Medline

Organisciak DT, Vaughan DK (2010) Retinal light damage: mechanisms and protection. Prog Retin Eye Res 29:113-134. CrossRef Medline

Parnas M, Katz B, Lev S, Tzarfaty V, Dadon D, Gordon-Shaag A, Metzner H, Yaka R, Minke B (2009) Membrane lipid modulations remove divalent open channel block from TRP-Like and NMDA channels. J Neurosci 29:2371-2383. CrossRef Medline

Pettitt TR, Wakelam MJ (1999) Diacylglycerol kinase epsilon, but not zeta, selectively removes polyunsaturated diacylglycerol, inducing altered protein kinase C distribution in vivo. J Biol Chem 274:36181-36186. CrossRef Medline

Pettitt TR, Martin A, Horton T, Liossis C, Lord JM, Wakelam MJ (1997) Diacylglycerol and phosphatidate generated by phospholipases C and D, respectively, have distinct fatty acid compositions and functions. Phospholipase D-derived diacylglycerol does not activate protein kinase $\mathrm{C}$ in porcine aortic endothelial cells. J Biol Chem 272:17354-17359. CrossRef Medline

Phillips AM, Bull A, Kelly LE (1992) Identification of a Drosophila gene encoding a calmodulin-binding protein with homology to the trp phototransduction gene. Neuron 8:631-642. CrossRef Medline

Pinot M, Vanni S, Pagnotta S, Lacas-Gervais S, Payet LA, Ferreira T, Gautier R, Goud B, Antonny B, Barelli H (2014) Polyunsaturated phospholipids facilitate membrane deformation and fission by endocytic proteins. Science 345:693-697. CrossRef Medline

Postma M, Oberwinkler J, Stavenga DG (1999) Does $\mathrm{Ca}^{2+}$ reach millimolar concentrations after single photon absorption in Drosophila photoreceptor microvilli? Biophys J 77:1811-1823. CrossRef Medline

Pumir A, Graves J, Ranganathan R, Shraiman BI (2008) Systems analysis of the single photon response in invertebrate photoreceptors. Proc Natl Acad Sci U S A 105:10354-10359. CrossRef Medline

Raghu P, Hardie RC (2009) Regulation of Drosophila TRPC channels by lipid messengers. Cell Calcium 45:566-573. CrossRef Medline

Raghu P, Colley NJ, Webel R, James T, Hasan G, Danin M, Selinger Z, Hardie RC (2000) Normal phototransduction in Drosophila photoreceptors lacking an InsP ${ }_{3}$ receptor gene. Mol Cell Neurosci 15:429-445. CrossRef Medline

Rawicz W, Olbrich KC, McIntosh T, Needham D, Evans E (2000) Effect of chain length and unsaturation on elasticity of lipid bilayers. Biophys J 79:328-339. CrossRef Medline

Reuss H, Mojet MH, Chyb S, Hardie RC (1997) In vivo analysis of the Drosophila light-sensitive channels, TRP and TRPL. Neuron 19:1249-1259. CrossRef Medline

Satoh AK, Xia H, Yan L, Liu CH, Hardie RC, Ready DF (2010) Arrestin translocation is stoichiometric to rhodopsin isomerization and accelerated by phototransduction in Drosophila photoreceptors. Neuron 67: 997-1008. CrossRef Medline

Schwiening CJ, Willoughby D (2002) Depolarization-induced pH microdomains and their relationship to calcium transients in isolated snail neurones. J Physiol 538:371-382. CrossRef Medline

Scott K, Becker A, Sun Y, Hardy R, Zuker C (1995) $G_{q}$ a protein function in vivo: genetic dissection of its role in photoreceptor cell physiology. Neuron 15:919-927. CrossRef Medline

Scott K, Sun Y, Beckingham K, Zuker CS (1997) Calmodulin regulation of Drosophila light-activated channels and receptor function mediates termination of the light response in vivo. Cell 91:375-383. CrossRef Medline

Shen LR, Lai CQ, Feng X, Parnell LD, Wan JB, Wang JD, Li D, Ordovas JM, Kang JX (2010) Drosophila lacks C20 and C22 PUFAs. J Lipid Res 51: 2985-2992. CrossRef Medline

Song Z, Juusola M (2014) Refractory sampling links efficiency and costs of sensory encoding to stimulus statistics. J Neurosci 34:7216-7237. CrossRef Medline

Song Z, Postma M, Billings SA, Coca D, Hardie RC, Juusola M (2012) Sto- 
chastic, adaptive sampling of information by microvilli in fly photoreceptors. Curr Biol 22:1371-1380. CrossRef Medline

Stark WS, Lin TN, Brackhahn D, Christianson JS, Sun GY (1993) Phospholipids in Drosophila heads: effects of visual mutants and phototransduction manipulations. Lipids 28:23-28. CrossRef Medline

Tang S, Guo A (2001) Choice behavior of Drosophila facing contradictory visual cues. Science 294:1543-1547. CrossRef Medline

van Hateren JH (1997) Processing of natural time series of intensities by the visual system of the blowfly. Vision Res 37:3407-3416. CrossRef Medline

Vásquez V, Krieg M, Lockhead D, Goodman MB (2014) Phospholipids that contain polyunsaturated fatty acids enhance neuronal cell mechanics and touch sensation. Cell Rep 6:70-80. CrossRef Medline

Wang T, Xu H, Oberwinkler J, Gu Y, Hardie RC, Montell C (2005) Light activation, adaptation, and cell survival Functions of the $\mathrm{Na}^{+} / \mathrm{Ca}^{2+}$ exchanger CalX. Neuron 45:367-378. CrossRef Medline

Wardill TJ, List O, Li X, Dongre S, McCulloch M, Ting CY, O'Kane CJ, Tang S, Lee CH, Hardie RC, Juusola M (2012) Multiple spectral inputs improve motion discrimination in the Drosophila visual system. Science 336:925-931. CrossRef Medline

Weijers RN (2012) Lipid composition of cell membranes and its relevance in type 2 diabetes mellitus. Curr Diabetes Rev 8:390-400. CrossRef Medline

Yau KW, Hardie RC (2009) Phototransduction motifs and variations. Cell 139:246-264. CrossRef Medline

Zinkler D, Bentrop J, Paulsen R (1985) Phospholipids of fly photoreceptor membrane: fatty acid and phosphoinositide metabolism. Verh Dtsch Zool Ges 78:303. 